\title{
Los actos jurídicos documentados en los textos legales visigodos
}

\author{
Olga Marlasca Martínez \\ Profesora doctora de Derecho romano \\ Universidad de Deusto
}

Recibido: 17.02 .2010

Aceptado: 18.06 .2010

\begin{abstract}
Resumen: En el presente artículo se pretende destacar la importancia que tuvo en el derecho visigodo el uso de la escritura en los más diversos ámbitos jurídicos. Para ello nos centramos fundamentalmente en dos textos legales de la época visigoda; en primer lugar, en el Código de Eurico, en el que algunos capítulos nos informan acerca de determinados negocios jurídicos que se redactaban por escrito; asimismo, en la Lex Visigothorum, en la que son numerosas las disposiciones que hacen alusión a los actos jurídicos documentados de todo tipo. Más concretamente, en relación con la citada lex, nos hemos centrado, en primer lugar, en los negocios jurídicos, así como en los actos forenses documentados. Finalmente se analizan los aspectos fundamentales relativos a la falsificación de los documentos regulados en el mencionado texto legal visigodo.

Palabras clave: Uso de la escritura; Derecho visigodo; actos jurídicos documentados; falsificación de documentos.

Abstract: In the present article we intend to highlight the importance that the use of writing in the most varied legal texts had in the Visigothic Law. With this purpose we focus mainly on two legal texts of the Visigothic times. Firstly on the Code of Eurico, in which several chapters show us certain legal transactions which were drawn up in writing. Likewise, on the Lex Visigothorum, where there are many provisions that recount documented legal acts of all types: more specificly, with regard to the mentioned Lex, we have focused firstly on the legal transactions as well as on the documented forensic acts. Finally, we analyse the main aspects related to the forgery of documents regulated in the mentioned legal Visigothic text.
\end{abstract}

Key words: Use of writing; Visigothic law; documented legal acts; forgery of documents.

Sumario: 1. Introducción.-2. Derecho visigodo. 2.1. Consideraciones previas. 2.2. Los actos jurídicos documentados en el Código de Eurico.- 3. Actos jurídicos documentados en la Lex Visigothorum. 3.1. Importancia de la escritura en el citado texto legal. 3.2. Requisitos generales para la validez de los documentos. 3.3. Ámbitos concretos de los actos documentados a los que se refire la Lex Visigothorum. 3.3.1. Negocios jurídicos. 3.3.2. Documentos forenses. 3.4. Falsedad de los documentos. 


\section{INTRODUCCIÓN}

En la actualidad, cuando hacemos una contratación importante, estamos habituados a unir a los acuerdos orales una documentación escrita. Podría decirse que en los tiempos actuales lo escrito está de un modo indisoluble ligado a los negocios de gran importancia ${ }^{1}$.

En el principio fue la oralidad y esta oralidad originaria de los actos jurídicos hizo que los documentos, cuando aparecen, estén funcionalmente limitados a la prueba de unos actos que ya se habían celebrado verbalmente; mientras que, por diversos caminos, la oralidad penetra en la misma estructura del documento ${ }^{2}$.

Si nos remontamos a la etapa romana, en el período arcaico los negocios más importantes están ligados a un rito típicamente oral con el pronunciamiento de palabras solemnes; pensemos, por ejemplo, en la mancipatio y la in iure cessio, que se presentan ligadas a un rito con los aspectos de arcaísmo que lo caracterizan; por otro lado, en el ámbito contractual, concretamente en la stipulatio, es el pronunciamiento de la palabras solemnes lo que hace nacer la obligación. Existe, por tanto, toda una relación con el rito oral, mientras que de la escritura no se habla ${ }^{3}$.

No obstante lo anterior, en dos campos concretos no tarda en manifestarse la escritura. Uno de ellos es el campo procesal y se refiere a la fórmula: la pretensión del demandante y las posibles alegaciones del demandado se redactan en un escrito que adquiere una gran relevancia en relación con un mundo de ritos orales.

El otro caso tiene relación con el testamento ${ }^{4}$. Precisamente, uno de los primeros negocios que se habrían reflejado por escrito es el testamento. Las tablillas testamentarias ${ }^{5}$ en las que se contenía habían tenido en sus orígenes valor probatorio, dado que el testamento en cuanto negocio continuaba siendo oral ${ }^{6}$.

\footnotetext{
${ }^{1}$ M. Amelotti, «Negocio, Documento y Notario en la evolución del Derecho romano», Anales de la Academia Matritense del Notariado. Tomo XXIX, p. 135

${ }^{2}$ Cf. A. Rodríguez Adrados, La persistencia histórica de la oralidad en la escritura pública, Madrid, 1996, p. 10.

${ }^{3}$ Sobre el particular, M. AmelotTI, «Negocio, Documento y Notario en la evolución del Derecho romano», ob. cit., pp. 135-136.

${ }^{4}$ En la Ley de las Doce Tablas no se encuentra ninguna alusión a la escritura; por otro lado, Tito Livio, en su obra $A b$ urbe condita VII, 3, dice concretamente que en el año 360 a. C.: «rarae per ea tempora litterae erant».

${ }^{5}$ Muy pronto surgieron una clase de profesionales especializados en la redacción de testamentos, a los que se denominaba testamentarii; entre otros, véase, A. FERNÁNDEZ DE BUJÁN, «A propósito del oficio de tabellio como jurista práctico en la experiencia jurídica romana», en Liber amicorum Juan Miquel. Estudios romanísticos con motivo de su emeritazgo, Barcelona, 2006, p. 306, nota 7.

${ }^{6}$ Ibídem.
} 
En definitiva, puede decirse que el uso de la escritura para documentar negocios jurídicos privados, salvo el caso mencionado del testamento, fue extraño a los romanos y, si más tarde se utilizaron, ello se debió al influjo de modelos grecohelenísticos en los que su empleo fue muy usual y extenso ${ }^{7}$. En Roma se advierte esta influencia ya a principios de la República ${ }^{8}$; conviene, no obstante, distinguir entre forma escrita, cuya observancia es esencial para la validez del negocio, de aquella otra que solamente se usa para constituir documentos probatorios. La forma escrita solo muy raramente es exigida en Derecho clásico: para el contrato literal, para el testamento escrito y en la fórmula procesal civil ${ }^{9}$.

Por el contrario, en la época postclásica ${ }^{10}$ la práctica de consignar en documento todo negocio jurídico importante, debido al influjo helenístico, fue tan extendida y general que, a causa de las concepciones del derecho romano vulgar, la observancia de la forma escrita fue considerada como requisito esencial de validez de todo negocio jurídico ${ }^{11}$. De manera que puede afirmarse que el «hecho notorio de que los documentos tengan en el derecho romano postclásico mucha mayor importancia que en el clásico está en

${ }^{7}$ La importancia concedida a la escritura de los contratos en Grecia explicaría la significación de los profesionales que cumplían en Grecia la función notarial, y su reconocimiento como titulares de una función pública. Por el contrario, la tardanza en aparecer la figura del notario se habría debido al carácter oral de la primitiva negociación en Roma, donde el testamento primitivo, la stipulatio y la mancipatio que constituyen las principales fórmulas de negocio tienen un carácter verbal; cf., por todos, A. RODRíGUEZ ADRADOS, «La persistencia histórica de la oralidad en la escritura pública», ob. cit., y la bibliografía allí mencionada.

${ }^{8}$ Los primitivos documentos recogían únicamente los acuerdos o la voluntad de las partes, a los que se añadía un sello (sigillatio) y los nombres de los intervinientes. Cf. FERNÁNDEZ DE BUJÁN, «A propósito del oficio de tabellio como jurista práctico en la experiencia jurídica romana», ob. cit., p. 305. En relación con la scriptura interior y exterior del documento, véase H. ANKUM, «Les tabellions romains, ancêtres directs des notaires modernes», en Atlas du Notariat. Le notariat dans le monde, Kluver-Deventer, 1989, pp. 10 ss.

${ }^{9}$ Entre otros, M. KASER, Derecho romano privado. Versión directa de la 5. ${ }^{a}$ edición alemana por José Santa Cruz Teijeiro, Madrid, 1968, p. 46.

${ }^{10}$ La importancia de la escritura en el período postclásico, tanto en los negocios translativos como en los obligatorios, está comprobada no solo en el Epitome sino en otros textos coetáneos, como las Sentencias de Paulo, el Codex Theodosianus y la Interpretatio. No se concibe contrato sin escritura. La cuestión de fondo está en si la escritura ha de entenderse como elemento esencial del negocio o simplemente como elemento probatorio.

${ }^{11}$ Según A. D’Ors, «Documentos y notarios en el derecho romano post-clásico», Centenario de la Ley del Notariado. Vol. I (1964), p. 91, « el predominio del documento está en relación con el fenómeno del vulgarismo que caracteriza la época-postclásica. Como es sabido, la elegantia iuris de la jurisprudencia clásica tenía un especial desdén por el problema de la prueba, por los facta, como algo que debe interesar al juez o al abogado elocuente, pero no al jurisprudente. De ahí también que el jurista no se aplique a la redacción de documentos». 
relación con la expansión de las influencias helenísticas que van de Oriente a Occidente» ${ }^{12}$.

Por otro lado, en el mundo romano, del primitivo carácter oral o verbal en la negociación, se pasa a la utilización de la escritura, primero privada, posteriormente firmada por testigos además de por las partes, y finalmente con la intervención de los tabelliones o notarios y de los funcionarios públi$\cos ^{13}$.

En Oriente, en relación con la escritura se presentaba una situación completamente diversa. El Oriente era la tierra del documento escrito. «Ya en el tiempo de los antiguos faraones los escribas, como bellísimas estatuas nos han transmitido, reflejaban todo por escrito, y así todo el restante mundo oriental, ya fuesen asirio-babilonios como poco a poco los griegos y los pueblos helenísticos» ${ }^{14}$. Era mediante la escritura como se realizaba el negocio: el documento era, por tanto, constitutivo y no solo probatorio. Según Amelott ${ }^{15}$, «los orientales habían llegado a una concepción modernísima, como es la del derecho incorporado al documento, por lo que transfiriendo el documento se transfería el derecho».

Por nuestra parte, después del presente apartado a modo de introducción, nos vamos a referir en las siguientes líneas a una serie de actos jurídicos documentados a los que se refieren los textos legales visigodos; por una parte, determinados negocios jurídicos de carácter privado que se redactan por escrito a los que hacen referencia el Código de Eurico, así como la Lex Visigothorum; asimismo, va a ser objeto de nuestra atención un gran número de documentos forenses regulados en las disposiciones de la citada ley de los visigodos, Por último, se analizan algunas disposiciones en las que se regula la falsificación de los documentos en el mencionado texto visigodo.

\section{DERECHO VISIGODO}

\subsection{Consideraciones previas}

El reino visigodo, antes de su establecimiento definitivo en Occidente, se constituyó en estrecha relación con el Imperio, al que desde antiguo

\footnotetext{
${ }^{12}$ Cf. A. D’Ors, «Documentos y notarios en el derecho romano post-clásico», ob. cit., p. 90 .

${ }^{13}$ Cf. A. FernándeZ de Buján, «Fides publica e instrumenta publice confecta en Derecho Romano», Revista de Estudios Latinos (Relat)1. 2001, pp. 189-200.

${ }^{14}$ M. AmelotTi, «Negocio, Documento y Notario en la evolución del Derecho romano», ob. cit., p. 137.

${ }^{15}$ Ibídem, p. 139, considera asimismo el citado autor que «para ciertos documentos del Egipto helenístico se puede intentar aplicar nuestra figura del título de crédito que pasa de uno a otro, del título al portador».
} 
venía prestando servicios militares de frontera bajo la fórmula del foedus ${ }^{16}$. El primer período del asentamiento de los visigodos en las Galias y en la parte noroeste de la Península, dominio que por el occidente llegó al parecer hasta Zaragoza, se inscribe en la estructuración del Imperio romano en la etapa anterior a la caída de Roma por los hérulos ${ }^{17}$. A partir del año 476, con la entrada de Odoacro en Roma, la situación sufrió transformaciones profundas que se manifestaron de forma desigual en los distintos territorios sobre los que estaban asentados los visigodos. Con Eurico, el primer monarca visigodo, y su hijo Alarico, se da un paso más al ocupar estos el lugar que antes había desempeñado el emperador, ejerciendo sus poderes y facultades. A partir de este momento es cuando podemos hablar propiamente de una legislación visigoda ${ }^{18}$. Finalmente hemos de decir que son los visigodos uno de los pueblos germánicos más romanizados de los que se asientan en el antiguo territorio del Imperio romano occidental. Entre los autores modernos no deja de reconocerse la profunda romanización de los reyes visigo$\operatorname{dos}^{19}$.

\subsection{Los actos jurídicos documentados en el 'Código de Eurico'²0}

En primer lugar, conviene destacar que la práctica de documentar los actos jurídicos «es recibida por los visigodos como tantos otros aspectos de

${ }^{16}$ Cf. R. GIBERT, «El reino visigodo y el particularismo español» en Cuadernos del Instituto Jurídico Español, 5. Estudios visigóticos, I, Roma-Madrid, 1956, p. 17 y las notas 6 y 7.

${ }^{17}$ Cf. entre otros, J. ORLANDIS, Historia de España. La España visigótica. Madrid, 1977, pp. 59 ss.; A. GarCía Gallo, «Consideración crítica de los estudios sobre la legislación y la costumbre visigodas», en $A H D E, 1974$, pp. 424 ss.

${ }^{18}$ Entre otros, puede verse Arangio RuIZ, Historia del Derecho romano, 4. ${ }^{\mathrm{a}}$ ed.; trad. esp. Madrid, 1989, pp. 448 ss.; L. A. García Moreno, Historia de la España Visigoda Madrid, 1989, pp. 317 ss.; LALINDE ABADIA, El derecho en la historia de la humanidad, Barcelona, 1982, pp. 38 ss.

${ }^{19}$ Sobre el particular, entre otros, D’ORs, «El Código de Eurico», en Cuadernos del Instituto Jurídico Español. Estudios Visigóticos, II, Roma-Madrid, 1960, p. 9.

${ }^{20}$ La legislación teodoriciana fue tan breve y circunscrita que, de acuerdo con San Isidoro, se puede considerar a Eurico como el primer legislador visigodo y de los pueblos germanos, ya que el Código de Eurico es la primera ley escrita de estos pueblos cf., entre otros, A. D’Ors, «El Código de Eurico», ob. cit., pp. 254 ss. Con su promulgación no se pretendió elaborar un ordenamiento jurídico completo; se trataba de una obra que tuvo aplicación preferente, porque realizó una adaptación de las leges y iura romanos a las necesidades de la práctica, para acabar con la duplicidad existente entre el derecho oficial y el de la práctica. En definitiva, «los monarcas visigodos comienzan a hacer suya una tradición que era común a todos los habitantes del Imperio y que ahora impulsan ya de forma autónoma». Cf. A. IgLesia FerReirós, La creación del Derecho. Manual I. Una historia de la formación de un derecho estatal español, Madrid, 1996, p. 205. En adelante, citamos los capítulos del Código de Eurico con las siglas CE. 
la cultura romana» ${ }^{21}$. En la época visigoda, según F. Dahn ${ }^{22}$, se extiende mucho el uso de la escritura continuando la práctica del Bajo Imperio y fomentada por la necesidad de primar la seguridad jurídica. «Los godos aceptaron de los romanos, entre otras muchas instituciones, el préstamo con interés, el testamento, los impedimentos matrimoniales de parentesco y, sobre todo, el múltiple empleo de documentos escritos en la vida jurídica ${ }^{23}$.

Más concretamente, en cuanto a los negocios jurídicos, el derecho visigodo adoptó la escritura como su forma preferente. Cualquier acto o contrato (testamentos, ventas, donaciones, préstamos, etc.) podía ser válidamente realizado con o sin escritura, siempre que mediare la intervención testifical, pero es comprobable una tendencia legislativa favorable a los actos escritos y restrictiva de la forma oral ante testigos ${ }^{24}$. Por otro lado, hay que destacar que la palabra scriptura es la que la legislación visigoda emplea con mucha frecuencia para referirse a cualquier tipo de documento jurídico ${ }^{25}$; sin embargo, en la práctica y a nivel vulgar prevalecen otros nombres, como pagina, charta o chartula ${ }^{26}$.

Precisamente en relación con la escritura en los negocios jurídicos, autores como Gibert aluden a la idea de que los germanos adoptaron del derecho romano la forma escrita en su realización «pero le imprimieron distintos caracteres que determinaron la variedad del régimen documental en la Edad Media» ${ }^{27}$. Nos referimos a continuación a algunos negocios jurídicos documentados a los que se refiere el texto euriciano.

El Código contiene varios capítulos dentro del Título De venditionibus en los que se regulan diversos aspectos relacionados con las ventas. Nos in169.

${ }^{21}$ Vid. C. PetiT, Fiadores y fianzas en derecho romanovisigodo, Sevilla, 1983, pp. 168-

${ }^{22}$ F. DAHN Westgothische Studien. Entstehungsgeschicte, Privatrecht, Strafrecht, Civil und Straf-Process und Gesamtritik der Lex Visigothorum, Würzburg, 1874, pp. 68-69. También SidONIO APOLINAR, Epístolas 4,24; 6,4; 7,2.

${ }^{23}$ Vid. K. Zeumer, Historia de la legislación visigoda. Trad. esp. por Carlos Clavería, Barcelona, 1944, p. 65. Sin embargo, SCHWERIN, «El derecho español más antiguo», en $A H D E$, I, (1924), p. 43, al referirse al uso de los documentos que no es originariamente germano, establece que «sigue siendo problemático si los visigodos toman el uso de documentos escritos del griego o del romano».

${ }^{24}$ Entre otros, J. Bono, Historia del Derecho Notarial español, Tomo 1. La Edad Media, Madrid, 1974, p. 83.

${ }^{25}$ Hay dos títulos muy significativos en la ley de los visigodos: LV 2,5, cuya rúbrica es De scripturis; por otro lado, en LV 7,5, la rúbrica es la siguiente: De falsariis scripturarum; además existen otras disposiciones en sedes distintas de la mencionada ley visigoda.

${ }^{26}$ Cf. A. García Gallo, «Los documentos y los formularios jurídicos en España hasta el siglo XII», en Anales de la Academia Matritense del Notariado. Tomo 22, vol. I (Homenaje a R. Núñez Lagos), p. 141.

${ }^{27}$ R. GIBERT, «Prenotariado visigótico», ob. cit., pp. 12-13. 
teresa destacar la primera disposición del citado título; concretamente, se trata de la que se recoge en CE $286^{28}$ que comienza diciendo lo siguiente: Venditio per scripturam facta plenam habeat firmitatem; después de establecer que la venta se perfecciona per scripturam, admite asimismo que se perfecciona por el praetium datum ante testigos. Por lo tanto, en primer lugar, para que la venta se considere perfecta es necesario que se redacte el correspondiente escrito; también es admisible que se pueda probar por medio de testigos que fue entregado el precio al vendedor.

Otro acto jurídico que ha de ser documentado tiene relación con las donaciones a las que se dedica el Título que lleva la rúbrica De donationibus; concretamente, en CE $307^{29}$ se refiere el texto euriciano a las donaciones entre cónyuges. Hace alusión el citado texto visigodo a la exigencia de la forma escrita de la donación nupcial; no obstante, en caso de necesidad la donación puede tener lugar oralmente ante dos o tres testigos. Considera D'Ors ${ }^{30}$ que la forma a la que se refiere el citado texto es la general de toda donación mortis causa, es decir, la forma del testamento ${ }^{31}$.

Según el citado autor, el término voluntas ${ }^{32}$ del texto euriciano alude claramente a la disposición testamentaria ${ }^{33}$. De esta forma, el capítulo mencionado distingue, por una parte, el testamento escrito, o firmado, al menos en presencia de testigos, y un testamento oral (nuncupativo) para caso de necesidad; el capítulo 307 citado se refiere a la forma de las donaciones testamentarias y en CE $308^{34}$ se refiere el legislador a las donaciones inter vivos

${ }^{28}$ El texto completo de CE 286 es el siguiente: Venditio per scripturam facta plenam habeat firmitatem. 2. Si etiam scriptura facta non fuerit, datum praetium testibus conprobatur, et emptio habeat firmitatem. 3. Venditio si fuerit violenter extorta, id est per metum mortis aut per custodiam, nulla valeat ratione.

${ }^{29}$ El texto completo contenido en el CE 307 establece lo siguiente: Maritus si uxori suae aliquid donaverit, de hoc quod voluerit scriptura sua manu signo sive subscriptione confirmet, ita ut duo aut tres testes ingenui subscriptores accedant; et sic voluntas ipsius habeat firmitatem. 2. Testes vero si ad scripturam non fuerint praesentes... us testium, voluntas non valeat. 3. Voluntas autem si necessitas est, coram duobus aut tribus testibus ore tantum ordinari potest. 4. Similis de uxoris voluntate que in maritum conferre voluerit donationis forma servetur.

${ }^{30}$ A. D’Ors, «El Código de Eurico», ob. cit., pp. 236-237.

${ }^{31} \mathrm{El}$ testamento fue un recurso jurídico que los visigodos tomaron muy pronto del Derecho romano; el Código euriciano utiliza el término testamentum en el Capítulo 308.

${ }^{32}$ A juicio de M. M. PÉREZ DE BEnAvides, El testamento visigótico, Granada, 1975, p. 78, «conviene precisar, sin embargo, que el citado capítulo puede también considerarse referido a las donaciones inter vivos de los cónyuges, autorizadas después del primer año de matrimonio»; del mismo modo, considera el autor que « el uso de la voz voluntas no implica necesariamente un carácter mortis causa, ni menos aún una confusión con el testamentum», cf. ibídem.

${ }^{33}$ Cf. A. D’Ors, «El Código de Eurico», ob. cit., p. 236.

${ }^{34} \mathrm{CE} 308$ : Res donata, si in praesenti traditur, nullo modo a donatore repetatur, nisi causis certis et probatis [...]. 
que se perfeccionan por la simultánea traditio. Otros autores no interpretan de la misma forma el capítulo 307 euriciano. Merea ${ }^{35}$ considera que es más razonable considerarlo «como una aplicación de los principios generales a este caso especial» (las donaciones entre cónyuges), ya que el objetivo de la ley, sigue diciendo el autor, debe haber sido «no propiamente fijar la forma de las donaciones, sino declarar irrevocables, contra lo que establecía el derecho romano, las donaciones entre cónyuges»; en cambio, Levy ${ }^{36}$, al interpretar el citado texto de Eurico considera que en el CE 307 se establece una forma especial para las donaciones entre cónyuges.

En definitiva, el texto euriciano al que nos estamos refiriendo, De donationibus, «puede ayudar a reconstruir el régimen del testamento, ya que su decadencia en el Bajo Imperio facilitó la aproximación entre ambos, que acredita el propio Eurico al hablar de similitudo. Pero semejanza no debe equivaler a confusión $»^{37}$.

Otro de los actos jurídicos documentados tiene relación con el testamento. Afirma Merea ${ }^{38}$ que el Código de Eurico muestra claramente que los visigodos, ya en el siglo v, conocían y practicaban el testamento, institución a la que se habían habituado en su convivencia con la población romana. Es cierto que no existe en el citado texto legal ninguna rúbrica que expresamente haga alusión al testamento; no obstante, algunos términos que aparecen en diferentes capítulos, como intestatus ${ }^{39}$, e incluso el término testamentum ${ }^{40}$ parecen acreditar su existencia; por otro lado, la redacción de algunos capítulos ${ }^{41}$ del texto euriciano hace pensar en que el Código de Eurico presupone la aceptación del testamento romano por parte de los visigodos ${ }^{42}$.

\footnotetext{
${ }^{35}$ P. Merea, Estudos de Direito Visigótico, Coimbra, 1948, p. 73.

${ }^{36}$ Cf. E. Levy, West Roman vulgar law. The law of property, Filadelfia, 1951, I, p. 165 .

${ }^{37}$ Sobre el particular, M. M. PÉREZ DE BENAVIDES, El testamento visigótico, ob. cit., p. 78.

${ }^{38}$ P. Merea, Estudos de Direito visigótico, ob. cit., pp. 107-108.

${ }^{39}$ Cf. CE 336.

${ }^{40}$ Cf. CE 308.

${ }^{41}$ Cf. CE 319; 329; 336.

${ }^{42}$ Sobre el particular, cf. M. Alonso y LAMBAn, «Las formas testamentarias en la Alta Edad Media de Aragón», en Revista de Derecho Notarial, 1954, n. ${ }^{\circ}$ 8, pp. 53 ss.
} 


\section{ACTOS JURÍdICOS DOCUMENTADOS EN LA 'LEX VISIGO- THORUM ${ }^{43}$}

\subsection{Importancia de la escritura en el citado texto legal ${ }^{44}$}

Las disposiciones de la LV contemplan la forma escrita en los más diversos ámbitos del derecho, en los términos que iremos viendo en los apartados siguientes. De ahí la protección legal a los actos regularmente documentados y al documento mismo, y la dura represión de la falsedad documental, aspectos a los que se refiere la ley. Además, «el uso de la escritura y la práctica de documentar los actos jurídicos está atestiguado incluso en las zonas rurales del reino de Toledo» ${ }^{45}$.

De esta manera, «todo el sistema del Derecho privado visigodo está dominado por la idea de la escritura y cada negocio jurídico puede ser conformado a través de una scriptura» ${ }^{46}$. Conviene destacar asimismo que en la ley visigoda aparecen aludidos los scriptores a los que se refiere como notarios publicos en la LV 7,5,947.

Por otro lado, aunque el uso del documento se extiende a todo negocio jurídico de alguna importancia ${ }^{48}$, en ocasiones, aclara la ley que no se trata de forma esencial para la validez del negocio (así, en ciertos casos se mantiene la duplicidad de formas, esto es, con o sin escrituras), puede verse la LV 5,4,3 en relación con la compraventa; asimismo, la disposición recogida en LV $10,1,2^{49}$, que declara válida la división de bienes hecha entre los her-

${ }^{43}$ Lex Visigothorum, ed. K. ZeUMER en Monumenta Germaniae Historica (Leges) vol. I, Hannover-Leipzig, 1902. En adelante, nos referimos a la Lex mencionada, con las siglas LV. La citada ley está dividida en 12 libros y estos en títulos y leyes con mayor o menor criterio sistemático. Esta división coincide con la del Código de Justiniano. El libro I trata de la ley y el legislador; el libro II, de la organización judicial y del procedimiento; libros III y IV, cuestiones de Derecho civil; libros VI-IX, Derecho penal; y libros X-XII, materias varias.

${ }^{44}$ La compilación legislativa promulgada por Recesvinto y cuya fecha de promulgación se suele colocar en el año 654 se la conoce por los diferentes nombres de Lex Visigothorum, Liber Iudiciorum o Liber Iudicum; debe destacarse además que la citada compilación se traduce al castellano en el siglo XIII con el nombre de Fuero Juzgo. Fuero Juzgo en Códigos antiguos de España, ed. M. Martínez Alcubilla, Madrid, 1885, es la edición que aquí hemos manejado.

${ }^{45}$ C. PETIT, Fiadores y fianzas en derecho romanovisigodo, ob. cit., p. 169.

${ }^{46} \mathrm{~J}$. Bono, Historia del derecho notarial español, ob. cit., pp. 80-81.

${ }^{47}$ La LV 7,5,9 lleva la siguiente rúbrica: De his, qui citra notarios publicos iussiones ac leges principum recitare vel scribere ausi fuerint. San Isidoro, en Etymol. IX, IV [27], al tratar del ordo curiae incluye al scriba publicus como el que escribe los documentos que se protocolizan en la curia municipal. Este cometido era el que desempeñaron los tabularii de la época romana.

${ }^{48}$ DAHN, Westgotische Studien, ob. cit., p. 69. También C. PETIT, «De negotiis causarum» II, AHDE, 56 (1986), p.116.

${ }^{49}$ La rúbrica es la siguiente: De non revocanda divisione inter fratres, etiam si sine scriptura sit facta, solum si idoneo teste convincat. 
manos, aunque no se haya documentado, siempre que se pueda probar por testigos; también en la LV 5,7,1 $1^{50}$ se refiere a la manumisión mortis causa, que puede tener lugar por escrito o de forma oral ante testigos. En otras ocasiones, la ley prescribe la forma escrita como esencial (requisito ad solemnitatem) para la validez del negocio jurídico: así, por ejemplo, la disposición contenida en LV 5,2,7, procedente del Código de Eurico 307 sobre donaciones mortis causa entre cónyuges ${ }^{51}$. En otros casos la forma escrita (aunque no esencial) reporta ventajas procesales: cf. el contenido de la disposición en la LV 5,6,352.

Además de destacar la importancia de la escritura en los actos jurídicos de la Lex Visigothorum, conviene también subrayar que la palabra scriptura es la que la legislación visigoda emplea constantemente para designar cualquier documento jurídico; así, pueden citarse, entre otras disposiciones, las recogidas en la LV 2,5, bajo la rúbrica De scripturis valituris et infirmandis ac defunctorum voluntatibus conscribendis. También el título LV 7,5, De falsariis scripturarum, está destinado a la falsificación de los documentos; del mismo modo, en otras sedes de la ley, determinadas disposiciones se van a referir a cuestiones relacionadas con la escritura.

Otro aspecto digno de mencionar en relación con el documento escrito al que se refiere la citada ley de los visigodos es que este es intangible en teoría; ello se pone de manifiesto en una ley de Chindasvinto recogida en la LV 2,5,5, donde se prohíbe a un otorgante oponerse a un pacto o plácito que estuviera puesto por escrito de forma legítima, a no ser que hubiera sido obtenido a través de extorsión por un poderoso.

De esta manera, si las mismas partes que intervienen en el acto jurídico documentado se obligan a respetar lo pactado en la scriptura, se generaliza el uso -presente también en la contratación romana- de establecer en el documento una cláusula penal ${ }^{53}$.

De las ideas expuestas anteriormente, se constata la importancia que el derecho de la Lex Visigothorum reconoce a los actos escritos. A la vista de las disposiciones contenidas en la citada legislación visigoda, son muchos los aspectos relacionados con los documentos que pueden ser objeto de estu-

\footnotetext{
${ }^{50}$ La LV 5,7,1 tiene la rúbrica siguiente: Si mancipia sive per scripturam seu per testem manumittantur.

${ }^{51}$ En el CE 307, citado anteriormente (= LV 5,2,7) establece como necesaria en las donaciones entre cónyuges la intervención de dos o tres testigos (ingenuii) que estén presentes y que firmen con el donante la escritura de donación; en caso de necesidad la voluntad se puede disponer de palabra en presencia de dos o tres testigos. En relación con el carácter de estas donaciones, se ha hecho ya mención anteriormente a las diversas opiniones en la doctrina.

${ }^{52} \mathrm{La} \mathrm{LV} \mathrm{6,6,3} \mathrm{tiene} \mathrm{la} \mathrm{siguiente} \mathrm{rúbrica:} \mathrm{De} \mathrm{pignore,} \mathrm{si} \mathrm{pro} \mathrm{debito} \mathrm{deponatur.}$

${ }^{53}$ La estipulación penal se había convertido como en una cláusula de estilo, vid. E. LEVy, Weströmisches Vulgarrecht. Das Obligationnerecht, Weimer, 1956, pp. 131 ss.
} 
dio, tales como los requisitos para la validez de los documentos escritos, ámbitos concretos de los actos documentados -negocios jurídicos entre particulares, documentos forenses, etc.-, falsificación de los documentos, la contropatio, la cláusula penal inserta en algunos documentos, entre otros.

Por nuestra parte, en las siguientes líneas, después de una breve alusión a los requisitos para la validez de los documentos, abordamos a continuación una serie de ámbitos en los que se hace mención a los actos jurídicos documentados en la citada ley visigoda, así como algunos aspectos relativos a la falsificación de los documentos en los términos a los que se refieren determinadas disposiciones del mencionado texto legal visigodo.

\subsection{Requisitos generales para la validez de los documentos ${ }^{54}$}

En la Lex Visigothorum se redactó un título, el Título 5 del libro 2, especialmente dedicado a las escrituras. Interesaba regular el documento como prueba del negocio -requisitos de datación, firmas y signos- y no tanto la regulación de la prueba de documentos ${ }^{55}$. Hay que destacar asimismo que el documento hispano-visigodo es intangible en teoría (cumpliendo los requisitos pertinentes), como se ha dicho anteriormente.

De este modo, podemos hacer alusión a la disposición contenida en LV 2,5,5, citada supra, que establece, entre otras cosas, lo siguiente: Et ideo que pactis vel placitis continentur vel monstratur scripta, plenam habeant firmitatem. Se ha de señalar además que la validez genérica del documento está recogida en varias disposiciones de la ley, así, en LV 2,5,1: Quales debeant scripture valere; y LV 2,5,2: De pactis et placitis conscribendis, así como la LV 2,5,356 en los términos que vamos a referirnos a continuación.

Más concretamente, la disposición de Chindasvinto contenida en la LV 2,5, $1^{57}$, así como también la LV 2,5, $2^{58}$, antiqua $^{59}$, se refieren a la exigen-

${ }^{54}$ Sobre los requisitos para la validez de los documentos, cf., entre otros, O. MARLASCA, «Algunos requisitos para la validez de los documentos en la Lex Visigothorum», en Revue Internationale des Droits de l'Antiquité, Tome XLV (1998), pp. 563-584.

${ }_{55} \mathrm{Cf}$. C. PETIT, «De negotiis causarum» (II), ob. cit., p. 116

${ }^{56}$ LV 2,5,3: Ne incognitam sibi scripturam quisquis ille testis suscribere audeat.

${ }^{57}$ LV 2,5,1 (Chind.) (Recc.) Quales debeant scripture valere.- Scripture, que diem et annum habuerint evidenter expressum adque secundum legis ordinem conscripte noscuntur, seu conditoris vel testium fuerint signis aut suscriptionibus roborate, omni habeantur stabiles firmitate. En cuanto al origen de la presente ley hay que decir que se trata de una ley de Chindasvinto (642-653) que aparece en los términos citados en la edición hecha por Recesvinto de la Lex Visigothorum, y más adelante veremos el apéndice que se añade a la citada ley en la edición de Ervigio.

${ }^{58}$ LV 2,5,2, el texto de la ley es el siguiente: De pactis et placitis conscribendis.- Pacta vel placita, que per scripturam iustissime hac legitime facta sunt, dummodo in his dies vel annus sit evidenter expressus, nullatenus inmutari permitimus.

${ }^{59}$ Por lo que respecta a las disposiciones que llevan la rúbrica antiqua, sabemos que representan el substrato más antiguo dentro de las leyes que conforman la Lex Visigothorum. 
cia de que conste con toda claridad en los documentos escritos el día y el año (dies et annus) para su validez; también la Lex Baiuvariorum ${ }^{60} 16,16$ recoge los mismos requisitos de forma que encontramos en la mencionada Lex Visigothorum.

Además, la citada LV 2,5,1 establece la exigencia de la suscriptio del otorgante del escrito o de sus testigos para acreditar el contenido del documento. La misma disposición, en su edición ervigiana ${ }^{61}$, indica que si el otorgante no puede escribir por razón de enfermedad, intervenga en ese supuesto un suscriptor rogado ${ }^{62}$, elegido de entre los testigos, que suscribía ad vicem auctoris; posteriormente, si el otorgante recupera la salud y lo que testó desea que sea firme, en este caso es necesario que lo refuerce con la subscriptio. Establece asimismo la citada disposición que si el otorgante fallecía, en ese caso el subscriptor ad vicem, en el plazo de seis meses, debía cuidar de afirmar las escrituras suscriptas a se.

${ }^{60}$ Lex Baiuvariorum, edición de J. Merkel, Monumenta Germaniae Historica (MGH), LL,3 (Hannover, 1863). Se trata de la legislación bávara que suele datarse hacia la mitad del s. VIII y es tenida en cuenta por Zeumer para la reconstrucción de la legislación de Eurico, ya que considera que la ley bávara mencionada había tenido el Código euriciano como modelo y que presentaba en ocasiones una versión del citado Código de Eurico más auténtica que la procedente de las leges antiquae; cf., entre otros, R. UREÑA y SMENJAUD, La legislación gótico-hispana (Leges Antiquiores-Liber Iudiciorum). Estudio crítico, Madrid, 1905, pp. 243 ss.; K. ZEumer, Historia de la legislación visigoda. Trad. española por Carlos Clavería, Barcelona, 1944, pp. 28 ss.

${ }^{61}$ Pocos años después de la aparición del Código de Recesvinto se sintió ya la necesidad de acometer una nueva reforma. La revisión del Liber se lleva a cabo en la época de Ervigio (680-687) y lo promulga el monarca citado en el año 681. El sucesor de Ervigio, Égica, intentó realizar una nueva redacción, pero no se tiene constancia de que esta llegara a materializarse. Si bien se añadieron leyes suyas a los ejemplares oficiales de la Lex Visigothorum. A partir de finales del siglo VII juristas anónimos añaden a la Ley visigoda leyes de Recesvinto que no fueron tenidas en cuenta en la edición recesvindiana de la citada Lex, además de modificaciones y añadidos en los textos legales. Todas estas transformaciones sufridas por la edición ervigiana dan lugar a lo que se conoce con el nombre de redacción Vulgata de la Lex Visigothorum y han sido objeto de estudio por Y. GARCía LóPEZ, Estudios críticos y literarios de la Lex Visigothorum, Santiago de Compostela, 1991, pp. 75-474. Finalmente hay que decir que en el s. XIII se traduce la LV al castellano con el nombre de Fuero Juzgo. Afirma C. Zeumer, Historia de la Legislación Visigoda, ob. cit., pp. 88-89, que «el código empieza verdaderamente en el libro II, que lleva la rúbrica: De negotiis causarum y que trata preferentemente de la constitución de los tribunales y del proceso. Que sea aquí donde empieza verdaderamente el código es algo que queda señalado externamente con la invocación que precede al primer capítulo, II,1,1: IN NOMINE DOMINI...»; más adelante, hablando de la redacción ervigiana, establece: «La ley de publicación de Ervigio está al principio del verdadero código que empieza con el libro II,1,1, y nos informa con frases pomposas y retóricas, sobre el objeto y significación de la labor legislativa», ibídem, p. 97. También, sobre el particular, M. DíAZ y DíAZ, «La Lex Visigothorum y sus manuscritos. Un ensayo de reinterpretación « en $A D H E$, 46 (1976), pp.163-223, excluye este libro primero de la redacción originaria del Liber considerándolo una adición posterior. 
Es evidente que la subscriptio ${ }^{63}$ tiene por objeto acreditar (por el otorgante o los testigos) el contenido del documento. Por otra parte, el signum es mencionado con frecuencia (la disposición contenida en CE 307 ya se refiere a ella $)^{64}$ junto con la subscriptio. La subscriptio presupone alfabetismo; en cambio, el signum es sustitutivo de subscriptio para analfabetos ${ }^{65}$. Aquí el elemento esencial es un signo (señal, normalmente cruz) junto con el cual otro declara en forma objetiva.

Por otro lado, es necesario que los documentos no se hayan realizado por la fuerza o por amenazas (vis o metus), así aparece regulado en la disposición contenida en LV 2,5,9, antiqua $^{66}$, que ha podido ser tomada de dos disposiciones procedentes del CE 286 y 309 en relación con la compraventa y la donación respectivamente y su nulidad en el supuesto de haberse realizado por la fuerza o habiéndose infundido miedo.

Pasamos a referirnos a continuación a dos tipos de relaciones jurídicas, la donatio y la venditio ${ }^{67}$, que han podido ser realizadas de forma violenta $o$

${ }^{63}$ LV 2,5,1 (Erv.). Al texto anterior de la ley se añade en la edición ervigiana lo siguiente: simili quoque et ille sripture valore constabunt, quas etsi auctor suscribere egritudine obsistente non valuit, in eis tamen qui suscriptores accederent postulabit, sicque suscriptionem vel signum ad vicem illius auctoris ille, qui est rogatus, inpresserit, hoc tantum est observandum, ut si conditor talium scripturarum de hac ipsa egritudine, qua detinebatur, revaluerit, si hoc ipsud, quod in huiusmodi scripturis testavit, firmum esse voluerit, manu sua illud solita suscriptione conroboret, et sic plenam quod testare visus est obtineat firmitatem $[. .$.$] .$

${ }^{63}$ Vid. K. Zeumer, «Zum westgothischen Urkundenwesen, 1. Subscriptio und signum. 2. Die Schriftvergleichung» en Neues Archiv de Gesellschaft für ältere deutsche Geschichichtskunde, 24 (1898); formula el autor la doctrina del documento visigótico. La subscriptio en fuentes visigodas coincide con la subscriptio romana del Bajo Imperio. En relación con las firmas hay que decir que para garantizar su legitimidad el derecho visigótico tomó del romano la contropatio, o comparación de la firma de un documento con la de otros.

${ }^{64} \mathrm{Cf}$. la nota 29.

${ }^{65}$ K. ZeUMER, «Zum westgothischen Urkundenwesen», ob. cit., p. 17.

${ }^{66}$ LV 2,5,9 (antiqua). Se trata de una disposición contenida en el título 5: De scripturis valituris et infirmandis ac defunctorum voluntatibus conscribendis (título especialmente dedicado a las escrituras), contenido en el Libro 2 de la ley de los visigodos y cuyo texto es el siguiente: Quod omnis scriptura vel definitio, que per vim et metum extorta fuerit, valere non poterit.- Pactum, quod per vim extorserit persona potentior vel inferior, sive placita vel reliquas scripturas, id est, si ille, qui paciscitur aut sub gladio mortem forte timuerit, aut ne penas quascumque vel ignominia patiatur, vel certe si aliquam iniuriam passus fuerit, huismodi pactio vel scriptura quelibet nullam habeat firmitatem.

${ }^{67}$ Existen excelentes trabajos acerca de las mencionadas relaciones jurídicas; así, entre otros, E. LeVY, Weströmisches Vulgarrecht. Das Obligationenrecht, II, Weimer, 1956; P. MEREA, Estudos de Direito Visigótico, ob. cit., donde recoge uno de sus artículos «A doaçao per cartam no direito romano vulgar e no direito visigótico», pp. $63 \mathrm{ss}$; del mismo autor, en relación con la compraventa, puede verse: «Sobre a compra e venda na legislaçao visigótica», cf. ibídem, pp. 183 ss. 
habiéndose infundido miedo, en escritura o sin ella, y que tienen su regulación específica en la Lex Visigothorum. Seguimos el orden sistemático del texto legal visigodo en relación con los citados negocios jurídicos (donatio y venditio); nos referimos en primer lugar a la disposición contenida en la LV $5,2,1$ (donatio) y a continuación a la LV 5,4,3 (venditio), poniendo el énfasis fundamentalmente en la nulidad del negocio coaccionado.

En cuanto al contenido concreto de la LV 5,2,1, antiqua, tiene la siguiente rúbrica: Ne valeat violenter facta donatio. Hemos de destacar la alusión expresa que hace de las dos circunstancias, esto es, la vis y el metus que invalidan la donación, se haya celebrado por escrito (en cuyo caso no tiene validez el documento) o no se haya realizado por escrito.

La citada disposición, de clara procedencia euriciana ${ }^{68}$, se insertó concretamente dentro del título segundo, De donationibus generalibus, correspondiente al Libro 5 de la Lex Visigothorum, que trata De transactionibus y, como se ha dicho anteriormente, tiene su precedente en el CE 309, que establece lo siguiente: Donatio que per vim et metum probatur extorta, nullam habeat firmitatem.

La nulidad del negocio coaccionado se encuentra asimismo en la LV 5,4,3 (Recc. Erv.), antiqua ${ }^{69}$. Se trata aquí también de una disposición antiqua y su contenido se encuentra ya en el Código de Eurico, concretamente en CE 286, citado supra.

Ambas disposiciones (esto es, LV 5,4,3 y CE 286) coinciden al establecer que la venta se perfecciona per scripturam o por el praetium datum ante testigos, refiriéndose seguidamente a la nulidad de la venta en la que ha intervenido vis o metus, independientemente de que se haya realizado el contrato de compraventa per scripturam o se haya realizado de forma verbal ante testigos ${ }^{70}$. Además, a la vista del texto citado, concretamente la disposición que contiene el CE 286,3, aclara el concepto de vis de la siguiente forma: [...] id est, per metum mortis aut per custodiam (amenaza de muerte o retención de libertad) $)^{71}$.

${ }^{68}$ Sobre el particular, véase, entre otros, A. D’Ors, «El Código de Eurico», ob. cit., p. 239; R. UREÑA Y SMENJAUD, La legislación gótico-hispana, ob. cit., p. 356, donde al referirse a la transformación evolutiva de la legislación gótico-hispana alude a la procedencia euriciana de la LV 5,2,1.

${ }^{69} \mathrm{LV}$ 5,4, 3, antiqua, lleva la rúbrica siguiente: Ne valeat violenter facta venditio.- El contenido completo de la citada antiqua véase en la nota 91.

${ }^{70}$ R. FERNÁNDEZ ESPINAR, «La compraventa en el Derecho medieval español» en $A H D E$, 25 (1955), p. 335, establece que hay una marcada tendencia probablemente por influencia helenística a celebrar la venta por escrito.

${ }^{71}$ La disposición citada del CE 286,3 ha pasado casi literalmente a la Lex Baiuvariorum 16,2. Así, el título 16 de la citada ley, que lleva la rúbrica De venditionibus, en el lugar mencionado, segundo párrafo contiene lo siguiente: Venditio si fuit violenter extorta, id est aut metu mortis aut per custodiam, nulla ratione firma est. 
Por todo lo que se viene diciendo, es evidente la importancia que el derecho de la ley visigoda reconoce a los actos escritos y más concretamente al uso de la escritura en los negocios jurídicos, sin perjuicio de que se trate, normalmente, de formas probatorias que tienen su alternativa en los testigos (así

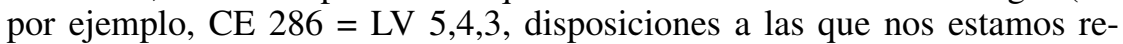
firiendo en el presente apartado). Además, analizando algunas Fórmulas Visigodas $^{72}$, son frecuentes las indicaciones que se hacen en los documentos en el sentido de que el acto se perfecciona por la escritura ${ }^{73}$.

Por otro lado, desde el punto de vista procesal, la prueba se ha convertido en el centro de atracción de la época y ello explica el triunfo del documento ${ }^{74}$ y justifica la regulación por la ley de la falsedad de documentos castigando esa conducta con ostensible dureza ${ }^{75}$.

En definitiva, «la mayor libertad y consiguiente facilidad en la redacción del documento a la vez que la mayor perdurabilidad de este al sustituirse las tablillas de cera por hojas de papiro o pergamino, con lo que su valor testimonial se prolonga más allá de la vida de los testigos del acto, contribuyen a generalizar cada vez más la utilización de los documentos» ${ }^{76}$.

${ }^{72}$ Fórmulas Visigodas, se trata de una colección compuesta por un total de 46 formularios jurídicos, que están clasificados por temas; la mayor parte de ellos son de derecho privado. Sobre las citadas Fórmulas Visigodas, cf., entre otros, A. GARCía GALLO, «Los documentos y los formularios jurídicos en España hasta el s. XII» en Anales de la Academia Matritense del Notariado. Tomo 22, vol. I (Homenaje a R. NúÑEZ LaGOS), pp. 134 ss. Más recientemente, E. CóRCOLES OlAITZ, «El contrato de compraventa a la luz de las Fórmulas Visigodas», en Revista Internacional de Derecho Romano, <www.ridrom.uclm.es> (Octubre, 2008) y la bibliografía allí citada.

${ }^{73}$ Entre otras, cf, FV 6: Quod per huius confectae libertatis paginam habeatis [...] FV 36: per huius precariae meae textum spondeo [... ]; cf. asimismo, FV 45, que lleva el siguiente título: Placitum, y en la que se establece, entre otras cosas lo siguiente: Unde mihi placuit hunc spontanea voluntate emittere placitum, per cuius texti formam sincerissima promito devotione [...] In quo placito, stipulatione subnixa, manu mea subscripsi et testibus a me rogitis pro firmitate tradidi roborandum. Se cita por la edición de K. ZEUMER, Formulae Visigothicae en Monumenta Germaniae Historica. Legum Sectio V. Formulae, Hannover, 1886, pp. 571-595.

${ }^{74}$ Cf. E. Levy, Weströmische Vulgarrecht. Das Obligationnenrecht, ob. cit., p. 46; también, A. IgLesia FERREIRós, Las garantías reales en el derecho histórico español. La prenda contractual: desde sus orígenes hasta la recepción del derecho común, Santiago de Compostela, 1977, p. 89.

${ }^{75}$ Cf. R. Gibert, «Prenotariado visigótico» ob. cit., pp. 38 ss. J. A. Alejandre García, «Estudio histórico del delito de falsedad documental», en AHDE, 42 (1972), pp. 117-187. En el mismo sentido, P. D. KING, Derecho y sociedad en el reino visigodo. Versión española de M. Rodríguez Alonso, Madrid, 1972, p. 132, considera que «dado el importante papel de los documentos se comprende la severidad con que debió castigarse su falsificación». En realidad, el delito concreto de falsificación de documentos fue subsumido en el crimen general de falsificación, ibídem.

${ }^{76}$ A. García Gallo, «Los documentos y los formularios jurídicos en España hasta el s. XII», ob. cit., p. 142. 


\section{3. Ámbitos concretos de los actos documentados a los que se refiere la 'Lex Visigothorum'}

Como se ha venido diciendo estaba muy extendido entre los visigodos el uso de la escritura y ello se evidencia, en primer lugar, en la redacción de determinados negocios jurídicos muy frecuentes en la realidad social visigoda. De esta manera, en las disposiciones de la ley visigoda que aquí se van a mencionar, vamos a destacar fundamentalmente el aspecto de la escritura, requisito esencial en unos casos, y no esencial en otros.

\subsubsection{Negocios jurídicos}

A) La promesa de matrimonio hecha entre los futuros contrayentes se regula en algunas disposiciones contenidas en la LV 3,1, que lleva la rúbrica, De dispositionibus nuptiarum. Concretamente, en la LV 3,1,377, se establece que la promesa de matrimonio, hecha ante ciertos testigos, habiendo dado o aceptado el anillo en concepto de arras, aunque no se haya hecho en escritura, no se puede quebrantar; está admitiendo, por lo tanto, la posibilidad de que la citada promesa se haya redactado en un escrito.

B) Otro acto jurídico tiene relación con la dote, y a ella se refiere la disposición recogida en LV 3,1,9, que tiene la rúbrica siguiente: Ut de quibuscumque rebus dos conscripta fuerit, firmitatem obtineat. En el citado texto, vemos que Recesvinto aconseja que la constitución de la dote se haga por escrito: dos conscripta; no obstante, como se desprende de la citada disposición, la escritura no era esencial. Ervigio ${ }^{78}$ hizo un añadido a la citada disposición ${ }^{79}$ y en él establece que la dignidad de las nupcias descansa en la escritura dotal y equipara la dos data a la dos conscripta en esa función.

Por otro lado, conviene destacar que el encuentro de la dote germánica con la donatio ante nuptias ${ }^{80}$ de procedencia romana dio lugar a la práctica a la que se refieren las Fórmulas Visigodas $14 .^{\mathrm{a}}-20{ }^{\mathrm{a} 81}$.

${ }^{77} \mathrm{LV} 3,1,3$, establece entre otras cosas que qui disposandi sunt, sive inter eorum parentes aut fortasse propinquos pro filiorum nuptiis coram testibus precesserit definitio, et anulus arrarum nomine datus fuerit vel acceptus, quamvis scripture non intercurrant, nullatenus promissio violetur.

${ }^{78}$ La LV 3,1,9, en la edición de Ervigio tiene la rúbrica siguiente: Ne sine dote coniugium fiat, et ut de quibuscumque rebus dos conscripta fuerit, firmitatem obtineat.

${ }^{79}$ En la LV 3,1,9 (Ervigio), se lee lo siguiente: Nam ubi dos nec data est nec conscripta, quod testimonium esse poterit in coniugii dignitate futura, quando nec coniunctionem celebratam publica roborat dignitas, nec dotalium tabularum hanc comitatur honestas?

${ }^{80}$ Considera P. Merea, Estudos de Direito Visigótico, ob. cit., p. 23, que «la dote en las fuentes visigóticas es el producto de la confluencia de la dote ex marito (wittum), propio del derecho germánico y, como tal, practicado tradicionalmente por los pueblos visigodos, con la donatio ante nuptias, difundida ampliamente en la sociedad del Bajo Imperio y a la que a veces se daba también la designación de dote $($ dos $) »$.

${ }^{81}$ Se cita por la edición de K. Zeumer, Formulae Visigothicae, ob. cit., pp. 581-585. 
C) Del mismo modo, las donaciones están contempladas en los textos visigodos: concretamente, partiendo del capítulo 307 del Código de Eurico, Chindasvinto dictó una disposición en la que se trata de forma extensa el régimen de la escritura; nos referimos a la disposición contenida en la LV 5,2,6 que lleva la siguiente rúbrica: De rebus traditis vel per scripturam donatis $^{82}$. A la citada ley, Ervigio le añadió tres pasajes en los términos a los que nos vamos a referir en las siguientes líneas.

Hay que destacar, en primer lugar, que la citada ley de Chindasvinto, a pesar de algunas dudas de interpretación que presenta, tiene el gran mérito de fijar el régimen jurídico de las donaciones de una forma bastante perfecta ${ }^{83}$; vamos a destacar a continuación la importancia del escrito de donación para su validez.

Más concretamente, en la redacción originaria, se establece en la disposición mencionada la equivalencia de la traditio con la entrega al donatario del escrito correspondiente, sin necesidad de una entrega directa de la cosa objeto de la donación ${ }^{84}$. Por lo tanto, no tiene ningún valor si el donatario no está en posesión de la cosa o del escrito de donación; no obstante, la ley no exige la entrega de la carta en mano, es suficiente con que el donante haga llegar la carta a poder del donatario o que este último esté en posesión del escrito por voluntad del donante.

De tal manera que si el donante demuestra que ni entregó ni envió la escritura, sino que le fue robada, todavía al donatario se le da la posibilidad de probar, mediante un testigo, que el escrito le fue entregado o puesto en su poder por voluntad del donante, según establece la ley: [...] tunc ille, cui res donate sunt, per testem convincat, ab ipso donatore eandem aut traditam sibi aut directam vel ex eius volumtate in potestate sua redactam, et dum probaberit, stabilis habeatur.

${ }^{82}$ LV 5,2,6 (Recesvinto [Ervigio]) De rebus traditis vel scripturam donati.- Res donate, si in presenti tradite sunt, nullo modo repetantur a donatore. Quod si etiam provenerit, ut quod donatur longe, sit positum, pro id donatio evacuari non poterit; quia tunc videtur vera esse traditio, quando iam aput illum scriptura donatoris habetur, in cuius nomine conscripta dinoscitur. Hoc tantum observandum est, ut, si donator dixerit, nec dedisse nec direxisse scripturam, sed sublatam sibi fuisse, tunc ille, cui res donate sunt, per testem convincat, ab ipso donatore eandem aut traditam sibi aut directam vel eius volumtate in potestate sua redactam, et dum probaberit, stabilis habeatur [...].

${ }^{83}$ Cf. P. Merea, Estudos de Direito Visigótico, ob. cit., p. 75.

${ }^{84}$ En el Fuero Juzgo 5,2,6, lleva la rúbrica: De las cosas que son dadas por escripto y establece a continuación lo siguiente: Las cosas que son dadas luego de mano, en ninguna manera non las deve demandar aquel que las dió. E si avinier por aventura que la cosa que es dada sea luenne, si es dada por escripto, non deve por ende ménos valer, que estonz. semeia la donacion perfecta [...]. 
En este lugar Ervigio ${ }^{85}$ ha insertado un primer añadido en el que se dice que, si no tiene lugar la citada prueba, se ha de exigir al autor del escrito que jure que no entregó ni envió el citado escrito ni tampoco por su voluntad llegó a poder del donatario. Con el citado juramento la pretendida donación quedaba sin efecto.

En la edición recesvindiana de la ley se dispone además que el donatario que no recibió la carta en vida del donante tiene la facultad de reclamar a sus herederos lo que le fue donado, ya que habiendo conservado el donante el escrito ello indica su voluntad de realizar la donación: [...] Quoniam iustum omnino est, ut talis scriptura robor plenitudinis habeat, quam vivens donator ita salvabit, ut nequaquam videatur aliquatenus inmutata.

Ahora bien, a continuación, en otro añadido de Ervigio ${ }^{86}$ a la citada ley, se establece que si el autor del escrito no entregó en vida ni el escrito, ni la cosa, sino que la retuvo, y posteriormente modificó su voluntad, es esta última la que prevalece: [...] Nam si scripturam ipsam vel rem conditor, dum viveret, nullo modo tradidit [...]. Además, sigue diciendo la disposición citada que el donatario puede reclamar la donación cuya carta no le fue entregada ni tampoco modificada por el donante; si el donatario muere antes de recibir la cosa donada o la carta, en ese caso, la cosa pertenece al donante o a sus herederos.

Finalmente, Ervigio añadió a la ley a la que nos estamos refiriendo una última consideración: establece que si el donatario que recibió la cosa, por traditio o por escritura, está conforme con su retención por el donante y fallece antes que el donante, en ese supuesto podrá disponer de la cosa por testamento; si no hizo testamento, pasará a los herederos ab intestato: [...] Quod si intestatus discesserit, non ad donatorem, sed ad heredes eius, qui rem donatam percepit, res eadem sine dubio pertinebit.

En definitiva, la idea de la traditio, ya existente en el Bajo Imperio, continúa en las leyes visigodas, especialmente en la Lex Visigothorum, como se acaba de ver en las anteriores líneas; de esta manera, al lado de la entrega de la cosa, se admite, en especial para los bienes inmuebles, la donación per cartam. No se exige que se haga una traditio solemne (traditio cartae), sino que es suficiente para que el donatario adquiera la propiedad sobre la cosa

${ }^{85}$ El añadido de Ervigio se manifiesta de la siguiente manera: tunc ille, qui scripturam fecit, iuraturus est, quia eandem scripturam neque per se dedisset neque direxisset, nec per voluntatem suam factum esse, ut eadem scriptura in manus eius veniret, a quo eam videtur repetere, et sic invalida remanebit.

${ }^{86}$ Los párrafos que proceden del añadido de Ervigio aparecen en los siguientes términos: Nam si scripturam ipsam vel rem conditor, dum viveret, nullo modo tradidit, sed aput se retinuit, et voluntatem suam in postmodum inmutavit, illut potius firmissimum erit, quod post testationem non tradite scripture definisse cognoscitur [...]. 
que esté en posesión del escrito de donación con el consentimiento del donante ${ }^{87}$.

D) Las donaciones entre cónyuges están reguladas en la LV 5,2,788 = CE 307 y en ella se exige que se formalicen en un escrito ${ }^{89}$. La citada disposición está tomada en su integridad del capítulo euriciano mencionado; por lo tanto, como ya se ha visto en el apartado correspondiente, también la ley visigoda hace alusión a la exigencia de la forma escrita de la donación nupcial; no obstante, en caso de necesidad la donación puede tener lugar oralmente ante dos o tres testigos.

E) Otro de los negocios jurídicos documentados a los que se refiere la ley de los visigodos tiene relación con la compraventa ${ }^{90}$ : la disposición contenida en LV 5,4,3, antiqua $^{91}$, lleva la siguiente rúbrica: Ne valeat violenter facta venditio. En ella se establece que la venta se perfecciona per scripturam ${ }^{92} \mathrm{o}$ por el praetium datum ante testigos. En cuanto a la venta per scripturam, conviene destacar que «las escrituras serían redactadas una vez entregado el precio, por lo que estas serían el reflejo del negocio ya realizado y que generaría la obligación de entregar la cosa» ${ }^{93}$; por otro lado, el texto legal establece a continuación: ceterum, si etiam scriptura facta non fuerit, et datum pretium presentibus testibus comprobetur et plenam habeat emptio roborem; por lo tanto, se está refiriendo a la venta sin escritura que es igualmente válida ${ }^{94}$.

${ }^{87}$ Sobre el particular, P. MEREA, Estudos de Direito Visigótico, ob, cit., p. 79.

${ }^{88}$ Véase la nota 29.

${ }^{89}$ Solo en el caso particular de las donaciones entre cónyuges se exigía una escritura de donación. Considera al respecto P. D. KING, Derecho y sociedad en el reino visigodo, ob. cit., p. 129 que en ellas «el legislador tenía tal vez interés en proteger a los esposos contra las consecuencias de una generosidad espontánea pero desmedida».

${ }^{90}$ De las 46 fórmulas que componen la colección de las llamadas Fórmulas Visigodas, tres de ellas tienen relación con la compraventa, de la 11 a la 13; es un número escaso de fórmulas el que se recoge en la citada colección, habida cuenta de que se trata de un negocio jurídico cuya realización es muy habitual en cualquier sociedad. Sobre el particular, véase, E. CóRCOLES Olaitz, «El contrato de compraventa a la luz de las fórmulas visigodas», ob. cit., p. 3.

${ }^{91}$ LV 5,4,3 (Recc. Erv.), antiqua. Ne valeat violenter facta venditio.- Venditio per scripturam facta plenam habeat firmitatem. Ceterum, si etiam scriptura facta non fuerit, et datum pretium presentibus testibus conprobetur, et plenum habeat emptio roborem. Venditio vero, si fuerit violenter et per metum extorta, nulla valeat ratione. Es la misma idea que se puede leer en la Interpretatio de las Sentencias de Paulo; concretamente en 2,18,13(14), se establece: In contractibus emti et venditi, qui bona fide ineuntur, venditionis instrumenta superflue requiruntur, si quocumque modo res vendita, dato et accepto pretio, qualibet probatione possit agnosci.

${ }^{92}$ Según E. Levy, West Roman vulgar law. The law of property, ob. cit., p. 131, la importancia de la forma escrita empieza a hacerse notar a partir del siglo III, época en la que la compraventa, debido a la influencia helenística, adopta esta forma.

${ }_{93}$ Cf. Ídem, Weströmisches Vulgarrecht. Das Obligationenrecht (Weimer, 1956), p. 208.

${ }^{94}$ Por otro lado, una vez efectuado el pago, no podía impugnarse la validez de la venta alegando como motivo que el precio era demasiado bajo, cf. LV 5,4,7, antiqua: Si dicat quis, rem suma vili pretio vindidisse. 
Además, como ya se dijo anteriormente, la ley visigoda se refiere seguidamente a la nulidad de la venta en la que ha intervenido vis o metus, independientemente de que se haya realizado el contrato de compraventa per scripturam o se haya realizado de forma verbal ante testigos.

F) Por lo que respecta al testamento, como negocio jurídico mortis cau$s a$, es evidente que a la vista de las disposiciones que en la ley de los visigodos se refieren al testamento no existe en ella una exposición sistemática del citado acto jurídico. Las disposiciones que se refieren a él se encuentran dispersas en diferentes sedes del texto legal visigodo, a diferencia de la regulación de la sucesión ab intestato que está contenida en la $\mathrm{LV} 4,2$, bajo la rúbrica De successionibus ${ }^{95}$. Vamos a tener ocasión de ver en las siguientes líneas que los autores de las disposiciones acerca del citado negocio mortis causa se inspiran en modelos romanos, pero procuran adaptar el testamento romano a las necesidades de su tiempo ${ }^{96}$.

Son varias las disposiciones de la ley visigoda que aluden al testamento y están recogidas en diferentes sedes del citado texto legal: fundamentalmente, en LV 2,5, bajo la rúbrica De scripturis valituris et infirmandis hac defunctorum volumtatibus conscribendis; del mismo modo, las disposiciones contenidas en LV 4,5, De naturalibus bonis; por otro lado, en la LV 7,5, que lleva la rúbrica: De falsariis sripturarum, se sancionan con rigor la falsedad de los documentos, entre los que alude claramente a la falsificación, encubrimiento, etc. de los actos mortis causa contenidos en un escrito. También en la disposición que se encuentra recogida en la $\operatorname{LV~} 5,5,10^{97}$ se hace mención al testamento.

\footnotetext{
${ }^{95}$ Con frecuencia, las disposiciones contenidas en LV 4,2, aparecen precedidas de la conjunción condicional: si, «lo que parece indicar un estado jurídico en el que la práctica testamentaria sería el supuesto normal», cf. M. M. PÉREZ DE BENAVIDES, El testamento visigótico, ob. cit., p. 81.

${ }^{96}$ P. Merea, Estudos de Direito Visigótico, ob. cit., p. 119; en el mismo sentido, M. Alonso y Lamban, «Las formas testamentarias en la Alta Edad Media de Aragón», ob. cit., pp. 53 ss. considera que a partir del contenido de algunos capítulos del Código de Eurico (cf. 318, 319, 320 y 336), «resulta evidente que el citado Código presupone la aceptación del testamento romano por parte de los visigodos, sin que pueda decir con certeza las formas que fueron acogidas, dado el estado fragmentario del Código de Eurico, pero se trataba en todo caso de un testamento en tal estado de disgregación, que podía ser asimilado a cualquier acto de última voluntad».

${ }^{97} \mathrm{LV}$ 5,5,10 tiene la siguiente rúbrica: Cui debeant testamenta vel scripturae conmendate restitui. Por lo que respecta a la terminología acerca de este tipo de negocios mortis cau$s a$ en la LV, considera M. M. ${ }^{a}$ Pérez De BENAVIDEs, El testamento visigótico, ob. cit., p. 82 que «puede afirmarse que la terminología de la legislación visigótica hasta Ervigio sigue una línea paralela a la observada en el derecho romano postclásico, y que a partir de él empieza a producirse una confusión e inexactitud en el empleo de las palabras adecuadas».
} 
En primer lugar, la disposición contenida en LV 2,5,12, lleva la siguiente rúbrica: Qualiter confici vel firmari conveniat ultimas hominum volumtates $^{98}$. La citada ley recesvindiana, al inicio hace alusión a la escritura (suscrita por el otorgante y los testigos, o bien garantizada por sus signos); a continuación, se refiere a otra posibilidad: la voluntad del testador manifestada verbalmente ante testigos, que debe ser consignada por estos dentro del plazo de seis meses por juramento ante el juez ${ }^{99}$.

Más concretamente, por lo que respecta al testamento escrito ${ }^{100}$, la disposición a la que nos estamos refiriendo presenta dos formas de testamento: el suscrito por el testador y los testigos ${ }^{101}$ y el que solo es signado por ambas partes. El añadido a la citada ley por parte de Ervigio $^{102}$ va a hacer alusión a otra posibilidad: es el supuesto en que el otorgante no pueda firmar ni poner el signo, en cuyo caso podrá suscribirlo o poner el signo un tercero junto con los testigos correspondientes.

Por otro lado, las dos primeras formas indicadas son completadas en otro añadido que hace Ervigio a la citada ley, en el que establece entre otras cosas que los testigos están obligados a publicarlo dentro de los seis meses siguientes ante el sacerdos ${ }^{103}$. Además, en el caso de que el testador no haya suscrito el documento, sino que solo haya puesto su signo, uno de los testigos que lo suscribió deberá jurar que el citado signo fue puesto por el testador ${ }^{104}$. Establece también la ley que el citado escrito no se considera firme hasta que

${ }^{98}$ LV 2,5,12 (Recesvinto): Morientium extrema volumtas, sive sit autoris et testium manu suscripta, sive utrarumque partium signis extiterit roborata, sive tantumodo verbis coram probationem patuerit promulgata, omni pereniter valere subsistat [...].

${ }^{99}$ La disposición recesvindiana citada en la nota anterior se encuentra recogida en el Fuero Juzgo, concretamente, en FJ 2,5,11, que lleva la rúbrica De las mandas de los muertos, cuemo deven ser escriptas é firmadas, y en la que se hace mención a cuatro posibilidades válidas de testar en los términos siguientes: si algun omne faze manda de sus cosas por escripto, é si el escripto fuere confirmado de la mano del qui lo fizo é de las testimonias, ó de aquel que la faze; ó si aquel que faze la manda non sabe escrevir por su mano, é diere otro omne que escriva por él, ó que lo sennale el escripto; ó si algun omne faze su manda ante testigos sin escripto; cada una de estas quatro maneras de fazer manda deve valer [...].

${ }^{100}$ La práctica del testamento cerrado y sellado debe de haber desaparecido en esta época, cf. Merea, Estudos de Direito Visigótico, ob. cit., p. 118.

${ }^{101}$ La ley no hace mención al número de testigos; una constitución de Justiniano del año 534, en CJ 6,23,31, se refiere a la antiqua consuetudo rusticanorum, según la cual, si no era posible reunir siete testigos litteratae, el testamento era válido con menor número de testigos, incluso analfabetos.

${ }^{102}$ El añadido de Ervigio a la LV 2,5,12 se presenta en los siguiente términos: Seu etiam, etsi auctor suscribere vel signum facere non prevaleat, alium tamen cum legitimis testibus suscriptorem vel signatorem ordinationis sue instituat.

${ }^{103}[\ldots]$ ] infra sex menses iuxta legem aliam sacerdoti pateant publicande.

${ }^{104}$ Et si forsitan contigerit, ut in huismodi scriptures auctor, qui suscribere debuit, signum inpressit, hoc ipsud testis, qui in eadem scriptura suscriptor accessit, iurare curabit, quia signum ipsud a conditore factum extiterit. 
el que suscribió en lugar del testador y los testigos por él rogados afirmen ante el juez que contiene la voluntad del testador ${ }^{105}$.

Hay que destacar asimismo que la mencionada voluntad por parte de quien realiza testamento ha de estar libre de violencia y miedo, tal como se deduce de la disposición LV 2,5,9, antiqua, citada ya anteriormente, que, al referirse a omnis scriptura vel definitio, hay que entender que alude también al documento en el que se contiene el testamento.

Además, fallecido el testador, su voluntad ha de ser corroborada ante los testigos o la autoridad eclesiástica, así lo establece la disposición contenida en LV 2,5,14: Ut defuncti volumtas ante sex menses sacerdoti vel testibus publicetur.

$\mathrm{Al}$ testamento ológrafo ${ }^{106}$ se refiere expresamente la disposición contenida en LV 2,5,16 ${ }^{107}$, bajo la rúbrica De olografis scripturis. Reconoce la propia ley, como se puede observar en el contenido del texto, que existen ocasiones en las que es difícil encontrar los testigos que son precisos y en atención a ello se dicta la norma en la que se van a establecer una serie de requisitos para la validez del testamento ológrafo.

De esta forma, además del escrito de puño y letra del testador, al que se refiere la mencionada ley -manu propia scribat ea, que hordinare desiderat $t^{108}$, se han de tener en cuenta otras exigencias establecidas con carácter general en otras disposiciones: que conste con toda claridad el día y el año (dies et annus $)^{109}$ para su validez; se exige del mismo modo, la presen-

${ }^{105}$ El añadido de Ervigio a la citada LV 2,5,12 se expresa en los siguientes términos: Ille vero scripture, que sub tertii ordinis alligatione sunt edite, id est, in quibus advocatus a conditore legitimus testis suscripsit, tunc omni habebuntur stabiles firmitate, quando infra sex menses et ille, qui in eadem scriptura ad vicem morientis suscriptor accesit, et reliqui testes, qui ab eo rogati sunt, coram iudice condicionibus factis iuraverint, quod in eadem scriptura a se suscripta nulla sit fraus impresa [...].

${ }^{106}$ Considera P. Merea, Estudos de Direito Visigótico, ob. cit., p.118 que el testamento ológrafo debía de ser poco frecuente.

${ }^{107}$ LV 2,5,16, que lleva la rúbrica De olografis scripturis, establece a continuación lo siguiente: Qui interdum necessitas ita sepe concurrit, ut sollemnitas legum libere compleri non possit, adeo, ubi qualitas locorum ita constiterit, ut non inveniantur testes, per quos iuxta legum ordinem unusquisque suam adliget volumtatem, manu propia scribat es, que hordinare desiderat $[\ldots]$.

${ }^{108}$ La disposición citada en la nota anterior, se recoge en el Fuero Juzgo, concretamente, en FJ 2,5,15 y se manifiesta en los siguientes términos: [...] cada uno omne debe escrevir su manda con su mano.

${ }^{109}$ Cf. LV 2,5,1, así como también la disposición contenida en LV 2,5,2. Del mismo modo, la Lex Baiuvariorum 16,16, recoge los mismos requisitos de forma que se han visto en la Lex Visigothorum. En la disposición citada, FJ 2,5,15, hace necesario asimismo la datación del escrito: é notar y el dia y el anno en que faze la manda, según se manifiesta en la ley. 
tación del escrito en el plazo de seis meses después de fallecido el testador, ante el sacerdos o los testigos ${ }^{110}$.

Por otro lado, en el caso de circunstancias especiales, admite la ley de los visigodos otras formas de testamento. Una disposición de Chindasvinto alude al testamento redactado en viaje o in expeditione publica y está recogido en LV 2,5,13 ${ }^{111}$, bajo la siguiente rúbrica: Qualiter firmentur volumtates eorum, qui in itinere moriuntur ${ }^{12}$.

De esta manera, como dice la ley, el viajero que va de camino y el soldado que está en la campaña, estando en peligro de muerte, pueden hacer testamento ológrafo si no es posible contar con testigos ingenuos: [...] voluntatem, suam propia manu conscribat; dispone asimismo la ley que si no saben escribir o no pueden hacerlo por enfermedad, pueden manifestar su voluntad ante siervos, cuya lealtad deben comprobar posteriormente el obispo y el juez.

También podría decirse que en las leyes visigodas no se prescribe nada respecto a la forma interna del testamento: «el interés de los legisladores se centró exclusivamente en el problema de establecer la autenticidad de la escritura como expresión genuina de la voluntad del difunto» ${ }^{113}$. De esta manera, las disposiciones de la Lex Visigothorum no se refieren a la exigencia de determinados requisitos para la validez de los testamentos; los requisitos que son necesarios son comunes a todo tipo de documentos. No obstante lo anterior, «la práctica jurídica recogida por las fórmulas demuestra la existencia de ciertos elementos presentes en todos los testamentos, indicio de que, con toda probabilidad, en la práctica sí que puede ser intuida la existencia de cierto rigor formal» ${ }^{114}$.

G) Otro acto jurídico documentado tiene relación con la manumisión de esclavos. La ley de los visigodos a la que nos estamos refiriendo dedica el título contenido en la LV 5,7 al citado tema y lleva la siguiente rúbrica: De libertatibus et libertis ${ }^{115}$; la primera disposición del título mencionado, la

${ }^{110}$ Cf. LV 2,5,14, citada anteriormente, que exige con carácter general la presentación de la scripta voluntas defuncti ante sex menses.

${ }^{111}$ La LV 2,5,13 manifiesta lo siguiente: In itinere pergens aut in expeditione publica moriens, si ingenuos secum non habeat, voluntatem suam propia manu conscribat. Quod si litteras nescierit aut pre langore scribere non potuerit, eandem voluntatem servis insinuet, quorum fidem episcopus adque iudex probare debebunt [...].

112 Algunos textos en el Derecho romano se refieren al testamentum militis, cf., entre otros: D. 29,1,1 pr., así como una constitución de Justiniano, en C. 6,21,17.

${ }^{113}$ Cf. P. D. KING, Derecho y sociedad en el reino visigodo, ob. cit., pp. 130-131.

${ }^{114}$ Cf. E. Córcoles Olaitz, « Un ejemplo de testamento visigótico a la luz de los formularios jurídicos (FORMULAE WISIGOTHICAE. FORMULA 21)», Studia Iuridica, 88. O Direito das successoes: do Direito romano ao Direito actual, (Coimbra, 2006), p. 1195.

${ }^{115} \mathrm{Se}$ trata de un título extenso ya que contiene dieciocho disposiciones. 
LV 5,7, $1^{116}$, establece que es válida la manumisión cuando quien está en peligro de muerte lleva a cabo el citado acto liberatorio por medio de un escrito $\mathrm{o}$ ante testigos.

Terminamos el presente apartado haciendo alusión seguidamente a algunos otros aspectos relativos a los documentos escritos a los que se refieren las disposiciones visigodas. Por una parte, se requiere la capacidad jurídica

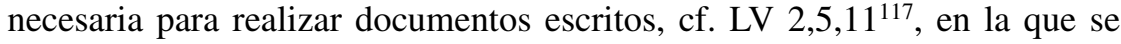
establece que no pueden realizar un documento escrito los menores de edad. Además, vemos que en la disposición contenida en LV 4,3,4 ${ }^{118}$ declara nulos los documentos escritos por personas que tienen limitada su capacidad, así como los escritos que recogen los actos realizados por los pupilos en favor de su tutor ${ }^{119}$.

Destacamos asimismo la disposición de la LV 2,5,3, que prohíbe suscribir un documento como testigo a quien antes no lo hubiere leído ni hubiere oído leerlo ante él, según se establece en el texto: [...] si non aut per se antea legerit, aut coram se legentem audierit. Se exige por tanto que el testigo conozca el negocio documentado, aunque no se dice que tenga que identificar a sus sujetos.

Finalmente, al depósito de documentos se refiere también la ley de los visigodos. Concretamente, la LV 5,5 lleva la rúbrica De commendatis et commodatis. Consta de diez disposiciones: las ocho primeras siguen el mismo orden de los correspondientes capítulos euricianos; posteriormente, Leovigildo añadió otras dos leyes y precisamente la última del capítulo, en LV 5,5,10 ${ }^{120}$, versa sobre el depósito de documentos, según se establece en la ley: testamenta, iudicia, pacta, donationes vel cetera alia.

\subsubsection{Documentos forenses}

En el presente apartado se pretende destacar el empleo y la importancia de los documentos escritos en el ámbito de los procesos. Como se va a tener ocasión de ver en los siguientes epígrafes, en la ley de los visigodos se encuentran aplicaciones concretas del principio de escritura en el mencionado ámbito: citaciones, declarationes in iuditio, prueba de testigos, tortura,

${ }^{116}$ LV 5,7,1, la rúbrica de la citada disposición se expresa en los siguientes términos: $S i$ mancipia sive per scripturam seu per testem manumittantur.

${ }^{117}$ LV 2,5,11 se manifiesta en los siguientes términos: Que scripture valere poterunt, si ab his facte fuerint, qui sunt in annis minoribus constituti.

${ }^{118}$ LV 4,3,4 tiene la siguiente rúbrica: Ne tutores ab eis, quos in tuitione habent, quascumque scripturas extorquere presumant.

${ }^{119}$ En términos parecidos se manifiesta el texto contenido en FJ 4,3,4, que lleva la rúbrica siguiente: De los que defienden los huérfanos non les fagan fazer nengun escripto.

${ }^{120}$ LV 5,5,10, antiqua: Cui debeant testamenta vel scripture conmendate restitui. 
redacción del fallo, etc., en los términos a los que vamos a hacer alusión a continuación.

Muchas de estas disposiciones se encuentran en el libro 2 de la Lex Visigothorum, que tiene la rúbrica De negotiis causarum y contiene cinco títulos, todos ellos referentes, en mayor o menor medida, al proceso ${ }^{121}$. Con los diversos tipos de documentos relativos a cuestiones en el ámbito procesal pueden hacerse, a su vez, tres grupos diferentes; en primer lugar, documentos emitidos por el juez, a los que vamos a referirnos seguidamente; documentos emitidos por los litigantes y, además, otro grupo heterogéneo de documentos forenses.

\section{1) Documentos Emitidos POR EL JUEZ}

Son varias las disposiciones visigodas que nos informan acerca de este tipo de documentos judiciales. Hay que tener en cuenta que «el juez del rey, al igual que el rey mismo cuando juzga, interviene activamente en el desarrollo de la controversia» ${ }^{122}$.

\section{A) Citación a juicio ${ }^{123}$}

En primer lugar, se refiere a ella una ley de Chindasvinto, contenida en LV 2,1,19, que lleva la siguiente rúbrica De his, qui admoniti iudicis epistula vel sigillo ad iudicium venire contemnunt. Se trata de una ley extensa ${ }^{124}$, en la que su autor reglamenta con detalle un principio procesal -la convocatoria del demandado por orden del juez-.

Conviene destacar, asimismo, que las reclamaciones serían nomalmente orales, y la citación judicial cursada al demandado - una epistula- constituiría el primer medio a disposición de este para conocer los términos de la controversia. Más concretamente, tras ser interpelado el juez por el demandante, procedía a enviar al acusado la pertinente citación a juicio (ad iudicum venire conpellat, según establece la ley), bajo la forma de una epistula sella-

${ }^{121}$ La base euriciana de estas disposiciones es muy reducida; los aspectos procesales ocupan poco la atención del legislador euriciano. Considera D'ORS al respecto que «toda esta materia seguía regida por el derecho romano y Eurico no tenía ninguna necesidad de legislar sobre ella», cf. «El Código de Eurico», ob. cit., p. 57.

${ }_{122}$ Cf. C. PeTIT, «De negotiis causarum»(II), AHDE, 56 (1986), pp. 85-86.

${ }^{123}$ El proceso visigodo es un proceso del rey, no hay apenas margen (legal) para la actuación parajudicial de los litigantes. El juez real lleva su dirección y una vez que el petitor o querellans presenta la demanda o la acusación, comienza por citar al demandado, forzándole a la comparecencia, cf. C. PETIT, «De negotiis causarum» (II), ob. cit., p. 20.

${ }^{124}$ Un análisis pormenorizado de la ley del monarca Chindasvinto puede verse en C. PETIT «De negotiis causarum» (II), ob. cit., pp. 37 ss. La citada ley se recoge en el Fuero Juzgo, concretamente, en FJ 2,1,17, con la siguiente rúbrica: De los que son lamados por letres del iuez, ó por seyelos, é non quieren venir. 
$\mathrm{da}^{125}$, donde posiblemente quedaban recogidos los términos de la reclamación y la fecha prevista para la comparecencia ${ }^{126}$. La entrega de la epistula, a cargo del sayón normalmente ${ }^{127}$, se realizaría, según el mismo texto legal, coram ingenuis personis, esto es, con la publicidad necesaria para constituir al demandado en condición de tal ante la comunidad ${ }^{128}$.

Del mismo modo, en cuanto a otra disposición de Chindasvinto, en LV $2,2,4^{129}$, que tiene la siguiente rúbrica $U t$ ambe partes causantium a iudice vel saione placito distringantur, quo possint ad prosequendum negotium pariter convenire, el contenido del texto se refiere a la apertura del procedimiento. Cuando las partes se obligan a comparecer ante el juez el día seña-

${ }^{125}$ Así lo interpreta P. D. KING, Derecho y sociedad en el reino visigodo, ob. cit., p. 115, nota 61 , cuando considera que «el hecho de que no varíe la frase epistula vel sigillum, que aparece cuatro veces en la ley, sugiere por su parte, que se trataba de una expresión técnica equivalente a epistula sigillata».

${ }^{126}$ Cf. C. Petit, «De negotiis causarum», ob. cit., p. 39.

${ }^{127}$ Según establece la LV 2,1,19, qui a iudice missus extiterit, entregaba la citación; el mensajero ordinario era sin duda el saio judicial, pero algunas veces, tal vez, lo hacía el demandante, cf. P. D. KING, Derecho y sociedad en el reino visigodo, ob. cit., p. 115. Además, como vemos en la disposición siguiente, en la LV 2,1,20: Si iudex interpellantem audire contemnnnat, vel utrum fraudulenter au ignoranter iudicium promat, se sanciona a los jueces que se negaban a cumplir los trámites de citación o demoraban injustificadamente la resolución del juicio.

${ }^{128}$ Sobre el particular, entre otros, C. PETIT, «De negotiis causarum», (II), ob. cit., pp. 37 ss; P. D. KING, Derecho y sociedad en el reino visigodo, ob. cit., pp. 114 ss.

${ }^{129}$ El texto completo de la disposición de Chindasvinto contenida en la LV 2,2,4 es el siguiente: Ut ambe partes causantium a iudice vel saione placito distringantur, quo possint ad prosequendum negotium pariter convenire.- Sepe neglegentia iudicum vel saionum, dum duarum partium sponsio non exigitur, una pars superflue convexatur. Nam ocurrente uno ad placitum et alio differente, non parvum dispendium uni parti concutitur. Statuimus ergo cunctosque iudices, vem quibuscumque iudicandi potestas est, commonemus, ut, quotiens pro quocumque negotioper sponsionem placiti constituendum est tempus, quando aut ubi causa dicatur vel debitum frotase reddatur, pars utraque, hoc est tam petentis quam petiti, ita placito distringantur, ut in constituto die aut per se aut per mandatarios suos presti sint in iudicio, qualiter aut propositum negotium finiatur aut debitum reformetur, et pars, que distulerit hac sese a prefinito dic suspenderit, aut si infirmitas eum vel itineris necesitas inpedierit, hoc ipsut iudici aut causídico suo non intimaverit neque ad peragendum negotium infra tempus alia lege constitutum occurrerit, stante negotio penam placiti sui illi cogatur exolvere, quem iuxta suma promissionem iudicio adesse constiterit. Quod si iudex hec aut saio adinplere neglexerit et unam partem placito distringens alteram pretermisserit, penam illa, quam illum damnare voluit, quem solum sub placito misit, de suo adinpleat, cui placitum visus est exegisse. Certe si in damno partis alterius placitum, quod ab altero exegit, alteri parti iudex vel saio reddiderit aut frotase ruperit vel absconderit, penam quidem, que in placito inserta fuerat, de suo illi persolvat, pro cuius causa conscriptum placitum esse constabat; actionem tamen ille, ciu conpetit, peragendam insistat. Damnum sane, quod per placitum in nomine iudicis vel saionis institutum esse dinoscitur, non ad saionem vel iudicem ex ómnibus pertinebit; sed, salvo negotio veritatem habentis, medietatem sibi exinde iudex vel saio et meditatem pars petentis per omnia vindicabit. 
lado mediante un placitum sponsionis -un compromiso escrito que incorpora la cláusula estipulatoria ${ }^{130}-$, los jueces y sayones deberán vigilar por el exacto cumplimiento de ese compromiso ordenando el pago de la pena prevista en el placitum a favor del contendiente que comparece y no puede seguir el pleito por la ausencia injustificada de la otra parte en el proceso ${ }^{131}$.

\section{B) 'Mandata iudicis'}

De nuevo, otra disposición de Chindasvinto en la LV 10,2,6, bajo la rúbrica De interruptione tricennii, tiene relación con la interrupción de la prescripción y la existencia de un litigio sobre la propiedad correspondiente. «No es difícil suponer que la ley pretende evitar violencias por parte del reclamante, y así ordena la intervención del sayón» ${ }^{132}$. Este ha de ser informado mediante el correspondiente escrito del juez suscrito por él mismo. Según se dispone en la ley: [...] ita ut, si iudex rem ipsam petenti saionis instantia preceperit consignari, per epistulam manu sua suscriptam eundem saionem iuxta modum subterius conprehensum informet ${ }^{133}$.

Otro ejemplo de documento emitido por el juez, en la modalidad de mandatum iudicis, lo recoge la ley visigoda en una disposición de Ervigio (1), concretamente en la LV 9,1,9: De susceptione fugitivorum, si dominus vel servus suscipiat alterius fugitivum ${ }^{134}$. El contenido de la ley ervigiana tiene relación con la denuncia que realiza el vecino al juez de haber recogido en su casa al esclavo fugitivo ${ }^{135}$. En definitiva, el juez debe suscribir el escrito que contenga todo lo que se haya averiguado al efecto ${ }^{136}$.

${ }^{130}$ Sobre la relación entre la stipulatio y el pactum, véase A. IGLESIA FerReIrós, Las garantías reales en el Derecho histórico español. La prenda contractual: desde sus orígenes hasta la recepción del derecho común. Tomo I, Santiago de Compostela, 1977, pp. 91 ss.

${ }^{131}$ En el FJ 2,2,4, se establece: Que el iuez ó el sayon deven constreñir ámbas las partes por recabdo, que vengan al pleito el dia del plazo.

132 Vid., ibídem, p. 63.

${ }^{133}$ En cuanto al escrito del juez para este supuesto, transcribimos lo que se dispone en la disposición del F J 10,2,6, cuando dice: [...] assíque el iuez debe mandar al sayon ó al mayordomo por unas letras fechas de su mano, segundo cuemo es contenido en fondo desta ley, que la faga guardar por sí.

${ }^{134}$ La LV 9,1,9: De susceptione fugitivorum, si dominus vel servus suscipiat alterius fugitivum. Establece a continuación: Ad cuius domum transiens advenerit fugitivus, si accepta ex incognito elemosina confestim alibi pertransierit, calumnia illi [...].

135 «esulta comprometido traducir sin más servus por esclavo en la época y las fuentes que consideramos; los cambios institucionales que acompañaron la aparición del feudalismo pasaban por la transformación del estatuto servil y la consiguiente atribución a los ser$v i$ de cuotas de capacidad que hubiera considerado aberrantes un jurista clásico», vid. C. PetiT, «De negotiis causarum» (II), ob. cit., p. 201 y la bibliografía que cita el autor en la nota 100 de la mencionada página.

${ }^{136}$ Sicque tota in unum collecta adque conscripta, iudex vel alii, qui adfuerint, manu sua hoc, quod perquisitum fuerit vel inventum, suscribere debeant. 


\section{C) 'Declaratio in iudicio'}

En relación con este tipo de declaración, también aquí, una disposición de Chindasvinto, recogida tanto en la edición recesvindiana, como en la ervigiana de la ley de los visigodos, concretamente en LV 2,1,25, tiene relación con la confesión en juicio: si el demandado reconoce ante el juez lo que le piden no es necesario seguir el procedimiento ya que, según se establece en la mencionada disposición: [...]conscribendum est a iudice suaque manu iudicium roborandum.

\section{D) 'Conditiones sacramentorum'}

Algunas disposiciones de la ley visigoda establecían que el juez determinase qué declaraciones habían de ser recibidas como pruebas (cf. las disposiciones contenidas en LV 2,2,5 y 2,4,2, entre otras). Estas declaraciones eran recogidas por escrito, adornadas de cláusulas juratorias y suscritas -tal vez- por el deponente. La documentación del testimonio que era prueba realzaba precisamente tal condición, disponiéndose en ciertos casos -si de rebus modicis mota fuerit actio- que su redacción y entrega a las partes desplazase el iudicium mismo ${ }^{137}$; puede verse al respecto la disposición contenida en LV 2,1,25 $5^{138}$, citada supra.

En otros casos, la imposibilidad de testimoniar personalmente conducía al apoderamiento de un tercero, el cual portaba la declaración bajo forma de conditiones juradas en su presencia, cf. LV 2,4,5; el citado portador deberá después jurar en el juicio que las conditiones que presenta han sido juradas por el testigo en su presencia. Precisamente, en el formulario visigótico al que ya se ha aludido anteriormente, la FV 39, Conditiones sacramentorum $^{139}$, presenta el modelo para la redacción de las conditiones testificales.

\section{E) 'Sententiae'}

La redacción por escrito de las sentencias es herencia romana aceptada por los hispano-visigodos ${ }^{140}$. La información sobre este tipo de acto procesal

${ }^{137}$ Sobre el particular, cf. C. PETIT, «De negotiis causarum», (II), ob. cit., p. 114.

${ }^{138}$ LV 2,1,25: Iudex, qualiter faciat iudicatum. La disposición equivalente en el Fuero Juzgo, está contenida en FJ 2,1,23: Del iuex cuemo debe iutgar. Entresacamos el siguiente apartado: E si aquel que es lamado que responda, manifestare antel iudex lo que demandan, non es menester que dé otra prueba el que demanda, aunque sea la demanda grand ó pquenna, y el iuex devéla faser escribir é robrar con so mano, que ninguna duda venga después sobre aquella cosa.

${ }^{139}$ Ed. K. Zeumer, Monumenta Germaniae Historica, ob. cit., p. 592.

${ }^{140}$ Según K. Zeumer, Historia de la legislación visigoda, ob. cit., p. 174, se trataría de una práctica romana, aceptada por la legislación visigoda y anterior a la disposición de Chindasvinto en LV 2,1,25; cf. CE 277; asimismo, LV 2,3,2, antiqua y LV 5,5,10, antiqua. 
documentado la proporciona la disposición de Chindasvinto contenida en la LV $2,1,25^{141}$, citada ya anteriormente. La mencionada disposición, bajo la rúbrica Iudex, qualiter faciat iudicatum, establece, en primer lugar, que la finalización del litigio tenía lugar normalmente por la sentencia del juez (iudicium) que debía recogerse por escrito presentibus utrisque partibus, y el texto de la sentencia debía ser entregado a cada uno de los litigantes suscrita por aquel ${ }^{142}$.

Contempla asimismo la citada disposición la posibilidad de que el demandado a quien se le exige el derecho que reclamaba el otro litigante, admitiera la reclamación: Quod si pars, que pro negotio quocumque compellitur, professa fuerit aput iudicem [...], según se establece en el texto legal. En este caso, el iudex redactaba y firmaba el escrito correspondiente que sustituía al iudicium o a las conditiones.

Otro aspecto de interés a destacar de la mencionada disposición es cuando establece que la documentación del fallo o similar había de servir para evitar nuevas reclamaciones de idéntico objeto, así cuando dispone que ne fortasse quelibet ad futurum ex hoc intentio moveatur.

141 LV 2,1,25, bajo la rúbrica, Iudex, qualiter faciat iudicatum, se manifiesta en los siguientes términos: Si de facultatibus vel de rebus maximis aut etiam dignis negotium agitetur, iudex,presentibus utrisque partibus, duo iudicia de re discussa conscribat, que simili texto et susscriptione roborata litigantium partes accipiant. Certe si de rebus modicis mota fuerit actio, sole condiciones, ad quas iuratur, aput eum, qui victor extiterit, pro ordine iudicii habeantu. De quibus tamen condicionibus et ille, qui victus est, ab eisdem testibus roboratum exemplaar habebit. Quod si pars, que pro negotio quocumque conpellitur, professa fuerit aput iudicem, non esse necessarium a petitore dari probationem, quamlibet parve rei sit actio, conscribendum est a iudice suaque manu iudicium roborandum, ne frotase quelibet ad furtum ex hoc intentio moveatur. Si vero, hordinante iudice, una pars testes adduxerit, et dum oportuerit eorum testimonium debere recipi, pars altera de iudicio se absque iudicis consultum subtraxerit, liceat iudici prolatos testes accipere, et quod ipsi testimonio suo firmaverint, illi, qui eos protulit, sua instantia consignare Nam ei, qui fraudulenter se de iuducio sustulit, producere testem alium omnino erit inlicitum; qui scilicet hoc sibi tantum noverit esse concessum, ut antequam testes illi, qi testimonium deerant, moriantur, si habuerit quod rationabiliter in eis accuset, patienter audiatur a iudice; et si accusatus testis fuerit evidenter convictus, eius testimonium ppro nihilo habeatur. Unde et si duo testes non remanserint, qui digni in ecodem testimonio maneant, ille, qui primum testem obtulerat, infra trium mensium spatium testes alios, qui ceptum negotium firment, inquireret non desistat. Quod si invenire nequiverit, rem universam ille recipiat, qui eam ante visus fuerat possedisse. Iudex sane de omnibus causis, que iudicaverit, exemplar penes se pro conpescendis controversiis reservare curabit.

${ }^{142}$ Según establece la LV 2,1,25, los iudicia tenían que ser firmados por el juez; en FV 40: Diiudicatio (edic. de K. Zeumer, en Monumenta Germaniae Historica, ob. cit., pp. 593-594) firman otros personajes; además del juez se refiere a la firma de otras personas. 


\section{2) DOCUMENTOS EMITIDOS POR LOS LITIGANTES}

\section{A) 'Libellus accusatorius'}

Salvo algunas referencias concretas, todo hace pensar que el proceso del Liber Iudiciorum no llegó a conocer el libelo acusatorio, forma escrita de demanda característica del derecho procesal romano tardío y presente en el Breviario $^{143}$; las reclamaciones serían normalmente orales, y la citación judicial cursada al demandado - una epistula - constituiría el primer medio a disposición de este para conocer los términos de la controversia. No obstante lo anterior, podemos referirnos a dos testimonios en contra de la generalización aludida $^{144}$

En primer lugar, hay que aludir a las noticias ofrecidas por $\mathrm{FV} 35^{145}$, correspondiente a una reclamación patrimonial motivada por la ocupación antijurídica de una cosa (probablemente inmuebles o ganados, pues salen a relucir los frutos), con el nomen iuris de libellum ${ }^{146}$.

Por otro lado, la ley de Chindasvinto recogida en la LV 6,1,6 $6^{147}$, tiene un marcado carácter penal (está inserta en el título De accusationibus criminum) y hace asimismo referencias a la forma de las acusaciones dirigidas al rey -una epistula, con suscripciones de testigos- para el caso en que no fue-

${ }^{143}$ Cf. M. KASER, Das römische Zivilprozessrecht, Múnich, 1966, pp. 460 ss., y la bibliografía allí citada.

${ }^{144}$ Sobre el particular, véase C. PETIT, «De negotiis causarum», ob. cit., (II), pp. 25 ss.

${ }^{145}$ Fórmulas Visigóticas, ed. K. Zeumer, en Monumenta Germaniae Historica, ob. cit., pp. 590-591.

${ }^{146}$ El contenido de FV 35: [...] quia rem iuris mei debitam, quam ille suo vitio extra discussionem iudicantis violentius usurpatione de meo dominio abstulit, nullos in eodem loco profligat labores, certe nec quicquam inibi augmentat, dum interim, manente iustitia, per legum statuta appetendo iuditiariam potestatem inter partes de veritate silentium imponatur; quod si transcens hanc coniurationem nostram, hoc quod in iure nostro pertinet in aliquod augmentaverit, sciat, se per iustitia, dum nostro dominio hoc ipsum probaverimus, debere secundum legum instituta de invasiones vel singulis annis frugum collectione ac sumptus per litis expensas nobis satisfacere et hoc, quod inibi profligavit, amittere. Factum libellum. Ed. de K. Zeumer, Formulae Visigothicae, ob. cit., pp. 590591.

${ }^{147}$ El texto de la disposición de Chindasvimto en la LV 6,1,6, bajo la rúbrica: Qualiter ad regem accusatio deferatur, establece, entre otras cosas, lo siguiente: Si quis principi contra quemlibet falsa suggesserit, ita ut dicat eum adversusu regem, gentem vel patriam aliquid nequiter meditatum fuisse aut agere vel egisse, seu in autoritabus vel preceptis regie potestatis aut eorum, qui iudiciaria ordinatione funguntur, fraudelenter quippiam inmutasse, adque etiam scripturam falsam fecisse vel recitasse falsamque monetam ferisse, sed et si veneficium vel maleficium aut adulterium uxoris aliene frotase prodiderit, horum vel similium criminum accusator, que ad capitis periculum vel rerum amissione pertinere videntur, si vera repperiantur que dixerit, nullam omnino calumniam sustinebit $[\ldots]$. 
se posible acceder directamente al monarca ${ }^{148}$. Es evidente que «los dos textos son favorables a la escritura en relación a querellas y demandas, a cuya redacción habría de contribuir precisamente el primero (FV35), pero no es difícil reducir la información a su restringido marco de procedencia» ${ }^{149}$.

\section{B) Petición de tortura por el litigante}

La regulación de la tortura se trata en dos disposiciones de Chindasvinto, luego modificadas en parte por Ervigio, y se encuentran recogidas en la LV 6,1,2, en la que se refiere a hombres libres, y en la disposición contenida en LV 6,1,5 ${ }^{150}$, que se refiere a la tortura de siervos.

Por lo que respecta a la primera ley mencionada, lleva la rúbrica siguiente Pro quibus rebus et qualiter ingenuorum persone subdende sunt questio$n i$. Nos interesa destacar la exigencia de la ley en que la solicitud de tortura se formalice en un escrito. De esta manera, previo juramento del actor de no obrar con fraude o malicia, la petición de tortura se realizaba por inscriptio ${ }^{151}$, documento de acusación con firma de tres testigos donde era descrito el delito imputado al reo y el acusador asumía la responsabilidad por una acusación no demostrada ${ }^{152}$.

Otro aspecto que destacamos de la citada ley tiene relación con lo siguiente: la regla general era que el acusador que instaba la tortura debía ser de status social igual o superior al del acusado; los nobles y dignatarios palatinos serían acusados por sus iguales, establece la ley: equalem sibi nobilitate vel dignitate palatini officii quicumque accusatum crediderit ${ }^{153}$.

${ }^{148}$ Considera C. PetiT, «De negotiis causarum», (II), ob. cit., p. 36 que «la información que da esta ley es valiosa, pues permite considerar que los delitos en ella recogidos -la traición, las falsedades de escritura y moneda, el envenenamiento, la hechicería y el adulterio uxorio, así como en general, aquellas acciones que ad capitis periculum vel rerum amissione pertinere videntur- eran los que llegaban a oídos del monarca, que actuaría en su condición de supremo».

${ }^{149}$ Vid., ibídem, pp. 25-26.

${ }^{150}$ LV 6,1,5: Pro quantis rebus et qualiter servus aut libertus tormenta portabunt. Por lo que respecta a los servi, la citada disposición admitía siempre la tortura para probar cualquier tipo de delitos.

${ }^{151}$ Según el texto: [...] Quod si probare non potuerit, coram principe vel his, quos sua princeps auctoritate preceperit, trium testium suscriptione roborata inscriptio fiat et sic questionis examen incipiat.

${ }^{152}$ Cuando se carecía de pruebas y no se autorizaba la tortura o no procedía, existía la posibilidad de recurrir al juramento. Como es sabido, el uso del juramento estuvo muy extendido en la sociedad visigoda. En definitiva, a base pruebas directas de la tortura, o por medio del juramento se llegaba por fin a una decisión judicial.

${ }^{153}$ Conviene destacar, además, lo siguiente: los ingenuos no potentes podían ser acusados y sometidos a tortura, siempre por otros ingenuos o por algún potentior, en los mismos casos capitales y también en el supuesto de furtum o demás actos delictivos castigados con una composición de trescientos, o más, sueldos, elevados más tarde en la edición ervigiana de la ley citada a quinientos sueldos. El inferior no podía hacer torturar a un potentior, quien, 


\section{C) 'Procurationes'}

En primer lugar hay que decir que la representación procesal es objeto de una regulación muy detallada en la ley de los visigodos, que dedica diez leyes en el título de la LV 2,3, De mandatoribus et mandatis. Además, la mayoría de ellas son antiquae, seguramente introducidas por Leovigildo en su revisión del código euriciano ${ }^{154}$. A continuación, se mencionan algunas disposiciones del citado título.

El representante en los litigios aparece designado con distintos nombres en una serie de disposiciones: así, es designado como adsertor en LV 2,3,2 y $3^{155}$ (se trata de dos disposiciones antiquae) y mandatarius en LV 2,2,4, en la ley de Chindasvinto; prosecutor en LV 2,3,7; por lo que respecta a la parte representada es siempre designado con el nombre de mandator.

El mandato otorgado al representante ${ }^{156}$ se documentaba mediante un escrito especial firmado por el dominus litis y por testigos ${ }^{157}$; esta exigencia legal encuentra una correspondencia exacta en algunos modelos de cartulae procurationis que con el nombre de iniuncto se refieren al poder dado por escrito y que ha transmitido el formulario visigótico ${ }^{158}$.

\section{3) OTRO TIPO DE DOCUMENTOS FORENSES}

\section{A) Documentos de prueba ${ }^{159}$}

«El auge de la contratación escrita hubo de tener, como es comprensible, profunda repercusión en el régimen de la prueba judicial ${ }^{16{ } \gg \text {. La declaración }}$

acusado sin pruebas, se libraba por juramento purgatorio. Pero lo que interesa aquí destacar es que el acusador que pide la tortura podía intervenir mediante representante, exigiéndose de este condición similar a la del acusado. Además, la iniunctio o apoderamiento, suscrita por tres testigos, había de contener la facultad de solicitud del tormento, de modo expreso, en todo caso.

${ }^{154}$ Cf. C. Petit, «De negotiis causarum, (I), ob. cit., p. 224. A. D’Ors, «El Código de Eurico», ob. cit., pp. 56-57, considera el título de mandatoribus, entre los que son totalmente nuevos, respecto al derecho euriciano.

${ }^{155}$ LV 2,3,3: Ut, qui per se causam non dicit, scriptis adsertorem informet.

${ }^{156}$ Los honorarios del mandatario se fijaban de antemano y se pagaban independientemente del resultado de la causa; si dejaba transcurrir más de tres meses sin entregar lo que correspondía al que le había encargado del caso, perdía todo derecho a ser remunerado, cf. LV 2,3,7.

${ }^{157}$ LV 2,3,3, antiqua. Lleva la siguiente rúbrica: Ut, qui per se causam non dicit, scriptis adsertorem informet. A continuación establece, entre otras cosas, lo siguiente: Si quis per se causam dicere non potuerit aut forte noluerit, adsertorem per scripturam, sue manus vel testium signis aut suscriptionibus roboratam, dare debebit; [...].

${ }^{158}$ Cf. FV 41, 42 y 43, ed. K. Zeumer, en Monumenta Germaniae Historica,. ob. cit., p. 594.

${ }^{159}$ Al lado de la prueba documental existía la testifical e, incluso, el juramento, cf. LV 2,1 23.

${ }^{160}$ A. D’ORs, «Documentos y notarios en el derecho romano postclásico», ob. cit., p. 109. 
oral de los testigos ${ }^{161}$ constituiría el grueso de las pruebas en las causas criminales, en tanto que en los asuntos civiles habría que disponer con frecuencia de pruebas documentales ${ }^{162}$. De este modo, el examen de testigos y consulta de documentos son las pruebas principales que permiten al juez real la resolución del proceso; a falta de estas, el juramento de la parte aparece como último instrumento de determinación de unos hechos que constituyen la base material del iudicium ${ }^{163}$. El triunfo de lo escrito supone forzosamente el de la prueba documental. En la LV 2,1,23, antiqua ${ }^{164}$, el juez solicita a los litigantes la presentación de las escrituras que son la base de sus declaraciones. En definitiva, «en la medida en que la controversia versara sobre la legalidad o el alcance de los actos documentados, el examen judicial de la escritura otorgada había de ser prueba decisiva para resolver el pleito» ${ }^{165}$.

B) Pacto de elección de juez

En la LV 2,1,15 ${ }^{166}$ de Recesvinto se prevé la citada disposición la elección de juez por consenso entre los litigantes; el pactum electionis debía tener lugar ante la presencia de tres testigos que lo confirmaban con sus signos o suscripciones en pacto escrito.

C) Remisión de causa a otro juez

Se contempla esta posibilidad en la ley de Chindasvinto recogida en la 2,2,7, que establece lo siguiente en esta rúbrica: Si quilibet ex alterius iudi-

${ }^{161}$ En cuanto a la capacidad legal para poder ser testigos, algunas leyes nos informan al respecto, estableciendo que cualquier persona libre podía testificar, con tal de que tuviera más de catorce años y estuviese en posesión de las facultades mentales cf. LV 2,4,12: De quibus annis poterunt testificare minores.

${ }_{162}$ Cf. P. D. KING, Derecho y sociedad en el reino visigodo, ob. cit., p. 126.

${ }^{163}$ Son numerosas las disposiciones que mencionan el juramento. Concretamente, la disposición de Ervigio, en la LV 2,1,23, concedió al juez la facultad de exigir el juramento a cualquiera de las partes, faltando la prueba; se establece lo siguiente: [...] In quibus tamen causis et a quo iuramentum detur pro sola investigatione iustitie, in iudicis potestate consistat.

${ }^{164}$ LV 2,1,23: Quid primo iudex observare debeat, ut causam bene cognoscat. Establece a continuación lo siguiente: Iudex, ut bene causa agnoscat, primum testes interroget, deinde iscripturas requirat, ut veritas possit certius inveniri, ne ad sacramentum facile veniatur. Hoc enim iustitie potius indagatio vera commendat, ut scripture ex ómnibus intercurrant et iurandi necesitas ses omnino suspendat. In his vero causis sacramenta prestentur, in quibus nullam scripturam vel probationem seu certa iudicia veritatis discussio iudicantis invenerit.

${ }^{165}$ Cf. C. PETIT, «De negotiis causarum», (II), ob. cit., pp. 116- 117.

${ }^{166}$ LV 2,1,15: Quod nulli liceat dirimere causas, nisi quibus aut princeps aut consensio volumtatis potestatem dederit iudicandi. 
cis potestate in alterius iudicis territorio habeat causam ${ }^{167}$. Más concretamente, se refiere la citada ley al supuesto de que la reclamación fuera presentada ante juez que no era el del demandado. La disposición de Chindasvinto establecía que si un hombre ingenuo o de condición servil tuviere que litigar en otro territorio, una vez presentada la demanda ante el juez, este habría de requerir a su colega de demarcación diferente, mediante epistula suscrita de su mano y signada ${ }^{168}$, para que atendiera sin demora la reclamación, según establece el texto legal: ut negotium querellantis audire et ordinare non differat; la citada epistula contendría los términos de la demanda y la identidad del demandado.

Además, hay que destacar de la mencionada disposición que la negativa a la orden del primer juez daba paso a la toma de prendas en los bienes del juez requerido, hasta el momento necesario para satisfacer al demandante.

\subsection{Falsedad de los documentos}

En los apartados anteriores nos hemos referido a una serie de disposiciones contenidas en la ley de los visigodos en las que se pone de relieve la utilización frecuente de la escritura en los más diversos campos jurídicos. La importancia de los documentos escritos se evidencia, además, en la existencia en la ley de un título dedicado expresamente a su falsificación y las sanciones previstas para los autores de acciones dolosas relacionadas con los documentos.

Concretamente, es en el Título contenido en LV 7,5, que lleva la rúbrica De falsariis scripturarum, donde se regulan los aspectos que se refieren a la falsificación de las escrituras; en el título siguiente, en LV 7,6, De falsariis metallorum $^{169}$, se refiere a la falsificación de los metales preciosos en general, incluidas las monedas.

${ }^{167}$ Véase la disposición contenida en la LV 2,2, 7, de la que transcribimos, a continuación, los primeros párrafos de la misma disposición: Si quisquam ingenuorum adque servorum extra territorium, in quo conmanent, in alterius territorio iudicis causationem habuerint, iudex, ad cuius ordinationem idem petitor pertinet, epistula sua manu suscripta adque signata eidem iudici dirigat, in qua premoneat, ut negotium querellantis audire et ordinare non differat $[\ldots]$.

168 Nos interesa destacar de la disposición mencionada el aspecto relativo al escrito que hace el juez comunicando la existencia de una reclamación al juez competente por razón del territorio. Para otros aspectos de interés que contiene la ley de Chindasvinto, véase, PETIT, C., «De negotiis causarum», (II), ob. cit., pp. 76 ss.

${ }^{169}$ En relación con los dos Títulos citados, conjetura D’ORS, A., «El Código de Eurico», ob. cit., p. 71, que pueden haber sucedido a un único título simplemente de falsariis, contenido en el Código de Eurico. 
No se pretende hacer en las siguientes líneas un estudio exhaustivo ${ }^{170} \mathrm{de}$ la falsificación de los documentos regulada en la ley visigoda, sino que nos vamos a centrar en algunas disposiciones del citado título, representativas de acciones dolosas relacionadas con los documentos. Concretamente, la primera ley del título, la LV 7,5,171, es una antiqua de Leovigildo que lleva la siguiente rúbrica: De his, qui regias autoritates et preceptiones falsare presumserint. La citada disposición castiga determinados actos relacionados con los documentos regios, reunidos en una serie de apartados: mutare, diluere, substrahere, interponere. Otra serie de actos, como alteración de los datos cronológicos del documento (tempus aut diem mutare sive designare), son también castigados en la ley; además, otro tipo de actuaciones dolosas tienen relación con sculpere vel imprimere sello falso. Por otro lado, la ley leovigildiana establece una serie de sanciones que son distintas, según la condición social y jurídica del autor que ha causado los citados actos dolosos.

Si la primera disposición del título tiene relación, como se ha dicho, con los documentos regios, la siguiente disposición se refiere a determinados actos relativos a cualquier tipo de escritura. Se trata de la ley de Chindasvinto, en LV 7,5,2, bajo la siguiente rúbrica: De his, qui scripturas falsa fecerint vel falsare temtaverint, en la que se establece una serie de sanciones, también en este caso sanciones diferentes según la condición social y jurídica del autor, cuando este realice determinadas conductas dolosas relacionadas con los documentos. En primer lugar, distingue la ley: facere, recitare, supprimere, proferre in iudico scripturam falsam; o actuaciones como supprimere, substrahere, disrumpere, designare, diluere scripturam veram, o sculpere, facer, imprimere signum adulterinum.

${ }^{170}$ Un estudio más pormenorizado del título de la LV 7,5, puede verse en O. MARLASCA MARTínEZ, «La regulación de la falsificación de los documentos en el Derecho romano y en la Ley de los Visigodos», en Estudios de Deusto. Vol. 47/1 Enero-Junio 1999. Sobre falsificación de documentos cf. asimismo los autores citados en la nota 75 .

${ }^{171}$ LV 7,5,1, antiqua: De his, qui regias autoritates et preceptione falsare presumserint. Seguidamente se manifiesta la citada disposición en los siguientes términos: Hi, qui in autoritatibus nostris vel preceptionibus aliquid mutaverint, diluerint, subtraxerint aut interposuerint, vel tempus aut diem mutaverint sive designaverint, et qui signum adulterinum sculpserint vel inpresserint: honestior persona mediam partem suarum facultatum amittat, fisci commodis profuturam; minor vero persona manum perdat, per quam tantum crimen admisit. Quod si contingat illos auditores vel iudices mori, ad quos audientia vel iussio destinata fuerat, aut episcopo loci aut alio episcopo vel iudicibus vicinis territorio illius, ubi iussum fuerat negotium terminare, liceat et datam preceptionem oferre et eosdem iudices negotium legaliter hac iustissime ordinare. 